\title{
A novel and compact review on the role of oxidative stress in female reproduction
}

\author{
Jiayin Lu, Zixu Wang, Jing Cao, Yaoxing Chen ${ }^{*}$ and Yulan Dong ${ }^{*}$
}

\begin{abstract}
In recent years, the study of oxidative stress (OS) has become increasingly popular. In particular, the role of OS on female fertility is very important and has been focused on closely. The occurrence of OS is due to the excessive production of reactive oxygen species (ROS). ROS are a double-edged sword; they not only play an important role as secondary messengers in many intracellular signaling cascades, but they also exert indispensable effects on pathological processes involving the female genital tract. ROS and antioxidants join in the regulation of reproductive processes in both animals and humans. Imbalances between pro-oxidants and antioxidants could lead to a number of female reproductive diseases. This review focuses on the mechanism of OS and a series of female reproductive processes, explaining the role of OS in female reproduction and female reproductive diseases caused by OS, including polycystic ovary syndrome (PCOS), endometriosis, preeclampsia and so on. Many signaling pathways involved in female reproduction, including the Keap1-Nrf2, NF-KB, FOXO and MAPK pathways, which are affected by OS, are described, providing new ideas for the mechanism of reproductive diseases.
\end{abstract}

Keywords: ROS, Oxidative stress, Reproductive diseases, Antioxidants, Imbalance, Female fertility, Signaling pathways

\section{Background}

Oxygen is a necessary element of aerobic life, and oxidative metabolism represents a principal source of energy. Cells have a defense system against ROS under aerobic conditions, and in healthy biology, there is an appropriate balance between pro-oxidants and antioxidants. OS occurs with the generation of excessive ROS or when the antioxidants' defense mechanisms are weakened [1-3]. The most important biologically ROS are superoxide anion $\left(\mathrm{O}_{2}^{-} \cdot\right)$, hydroxyl radical $(\cdot \mathrm{OH})$, peroxyl (ROO'), alkoxyl $\left(\mathrm{RO}^{\circ}\right)$ and hydroperoxyl $\left(\mathrm{HO}_{2}{ }^{\circ}\right)$. Free radical species are unstable and highly reactive, but they can become stable by acquiring electrons from lipids, nucleic acids, proteins, carbohydrates or nearby molecules, causing a cascade of chain reactions and resulting in cellular damage and disease [4-6]. Therefore, OS can cause DNA damage, lipids peroxidation and protein damage. Under normal circumstances, there are two types of antioxidants in the body: non-enzymatic antioxidants and enzymatic antioxidants. Enzymatic antioxidants include superoxide dismutase (SOD), glutathione

\footnotetext{
* Correspondence: yxchen@cau.edu.cn; ylbcdong@cau.edu.cn Laboratory of Neurobiology, College of Animal Medicine, China Agricultural University, Haidian, Beijing 100193, People's Republic of China
}

peroxidase (GPx), catalase (CAT) and glutathione reductase (GSR), which can cause reduction of $\mathrm{H}_{2} \mathrm{O}_{2}$ to water and alcohol. Non-enzymatic antioxidants are known as synthetic antioxidants or dietary supplements, including vitamin $C$, vitamin $E, \beta$-carotene, selenium, zinc, taurine, glutathione and so on [7].

OS is considered to be responsible for the initiation or development of pathological processes affecting female reproductive processes $[8,9]$, such as embryonic resorption, recurrent pregnancy loss, preeclampsia, intrauterine growth restriction (IUGR) and fetal death [10]. However, the relationship between ROS-induced OS and diseases is unclear and cannot be adequately investigated in human pregnancies because of self-evident ethical reasons. Therefore, animal models of both normal and disturbed pregnancies are essential for filling these important gaps in our knowledge. The normal level of ROS plays an important regulatory role through various signaling transduction pathways in folliculogenesis, corpus luteum oocyte maturation and feto-placental development [11]. However, ROS can sometimes exert damaging effects when overabundant. They have a close relationship with reproductive events, so tightly controlled ROS generation is an important process. It is one

(c) The Author(s). 2018 Open Access This article is distributed under the terms of the Creative Commons Attribution 4.0 International License (http://creativecommons.org/licenses/by/4.0/), which permits unrestricted use, distribution, and 
of the central elements of cell signaling, gene expression, maintenance of redox homeostasis and signal transduction pathways involved in cell function, growth, differentiation and death [12]. When keywords were searched in the NCBI and Web of Science databases, there were more than 100,000 articles on reproduction and oxidative stress, but there were only approximately 20,000 articles on the relationship between female reproduction and oxidative stress. There were more than 3000 articles about the mechanism, but there were only approximately 800 articles on uterine and ovarian diseases and oxidative stress. There is very little research on the mechanism of uterine and ovarian diseases and oxidative stress, only 30 articles, and review articles are rare. This review not only sheds light on the mechanism of action of oxidative stress under normal physiological conditions, but it also explores and speculates on the mechanisms of joint reproductive diseases, providing readers with more comprehensive content. The 133 articles selected in this article have a greater impact on the fields of reproduction and stress. By summarizing previous studies, a convincing review is offered.

The previous discussion of reproduction and oxidative stress was limited to individual diseases. This review aims to provide a comprehensive discussion of the role of oxidative stress in female reproduction, and it speculates on new mechanisms of action. This review mainly examines the available evidence for the involvement of cellular ROS-induced OS in pregnancy-related diseases, and it explores the new signaling pathways between OS and female reproduction.

\section{Reproductive processes}

It is well known that the development of ovarian follicles is a continuous process (Fig. 1). There are five stages in female mammals. During these stages, the structure of the endometrium undergoes some changes. Estrogen and progesterone are secreted via the ovaries and uterus and undergo changes during the estrus cycle. In addition, the basal body temperature also changes, while the thickness of the endometrium undergoes the corresponding transformation [13] (Fig. 2).

The combination of sperm and egg consists of three steps: corona radiata dissolution; zona pellucida dissolution; and egg fertilization and cortical reaction (Fig. 3). The process occurs in the ampulla portion of the fallopian tube. Pregnancy starts when the fertilized egg is formed. Human chorionic gonadotropin (HCG) increases first and then decreases. Both estrogen and progesterone are increased during pregnancy (Fig. 4). It is noted that the process of implantation is significant in reproductive events. The process includes contact, dissolution, invasion, wrapping and repair (Fig. 5). Ovarian function and blastocyst development from ovulation to implantation are common in many mammalian species after ovulation (Fig. 5) [14].

\section{Oxidative stress}

\section{Reactive oxygen species (ROS)}

ROS are a double-edged sword: they not only play important roles as secondary messengers in many intracellular signaling cascades, but they also exert indispensable effects on pathological processes involving the generation of excessive ROS. The three major types of ROS are superoxide anion $\left(\mathrm{O}_{2}^{-}{ }^{-}\right)$, hydrogen peroxide $\left(\mathrm{H}_{2} \mathrm{O}_{2}\right)$, and hydroxyl $(\cdot \mathrm{OH})$.

Most ROS are produced when electrons leak from the mitochondrial respiratory chain, also referred to as the electron transport chain (ETC) [15]. According to an estimate, up to $2 \%$ oxygen consumed can be diverted to the production of ROS formation by mitochondria, especially at complexes I and III [16]. The free radical superoxide anion $\left(\mathrm{O}_{2}^{-} \bullet\right)$ is formed by the addition of one electron to ground state dioxygen, but it is unstable in aqueous solutions due to its being able to react spontaneously with itself, producing hydrogen peroxide $\left(\mathrm{H}_{2} \mathrm{O}_{2}\right)$ and molecular oxygen $\left(\mathrm{O}_{2}\right)$ (reaction 1). It can reduce $\mathrm{Fe}^{3+}$ to $\mathrm{Fe}^{2+}$ and transform into $\mathrm{O}_{2}$ (reaction 2). $\mathrm{H}_{2} \mathrm{O}_{2}$ is not a free radical, but it is very harmful to cells because it is able to cross biological membranes and break down into the highly reactive hydroxyl radical $(\bullet \mathrm{OH})$.

The main source of hydroxyl radical is the metal-catalyzed Haver-Weiss reaction (reaction 3), the second of which is the Fenton-type reaction (reaction 4).

$$
\begin{aligned}
& \mathrm{O}_{2}^{-} \cdot+\mathrm{O}_{2}^{-} \cdot+2 \mathrm{H}^{+} \rightarrow \mathrm{H}_{2} \mathrm{O}_{2}+\mathrm{O}_{2} \\
& \mathrm{O}_{2}^{-} \cdot+\mathrm{Fe}^{3+} \rightarrow \mathrm{O}_{2}+\mathrm{Fe}^{2+} \\
& \mathrm{O}_{2}{ }^{-} \cdot+\mathrm{H}_{2} \mathrm{O}_{2} \rightarrow \mathrm{O}_{2}+\mathrm{OH}^{-}+\cdot \mathrm{OH} \text { (Haver-Weiss reaction) } \\
& \mathrm{Fe}^{2+}+\mathrm{H}_{2} \mathrm{O}_{2} \rightarrow \mathrm{Fe}^{3+}+\mathrm{OH}^{-}+\cdot \mathrm{OH} \text { (Fenton-type reaction) }
\end{aligned}
$$

\section{The defense mechanism against oxygen free radicals Primary defenses}

As we all know, SOD, CAT, GPx and GSR belong to the primary defense mechanism (Fig. 6). SOD catalyzes $\mathrm{O}_{2}{ }^{-}$• dismutation to produce $\mathrm{H}_{2} \mathrm{O}_{2}$ and $\mathrm{O}_{2}$ at a rate $10^{4}$ times higher than spontaneous dismutation at the physiological $\mathrm{pH}[17,18]$. CAT is the enzyme that removes $\mathrm{H}_{2} \mathrm{O}_{2}$ from the cell when the latter is at high concentrations (reaction 5) [19]. GPx is an enzyme that catalyzes the reduction of $\mathrm{H}_{2} \mathrm{O}_{2}$ and organic free hydroperoxides requiring glutathione as a co-substrate (reaction 6 and 7) 


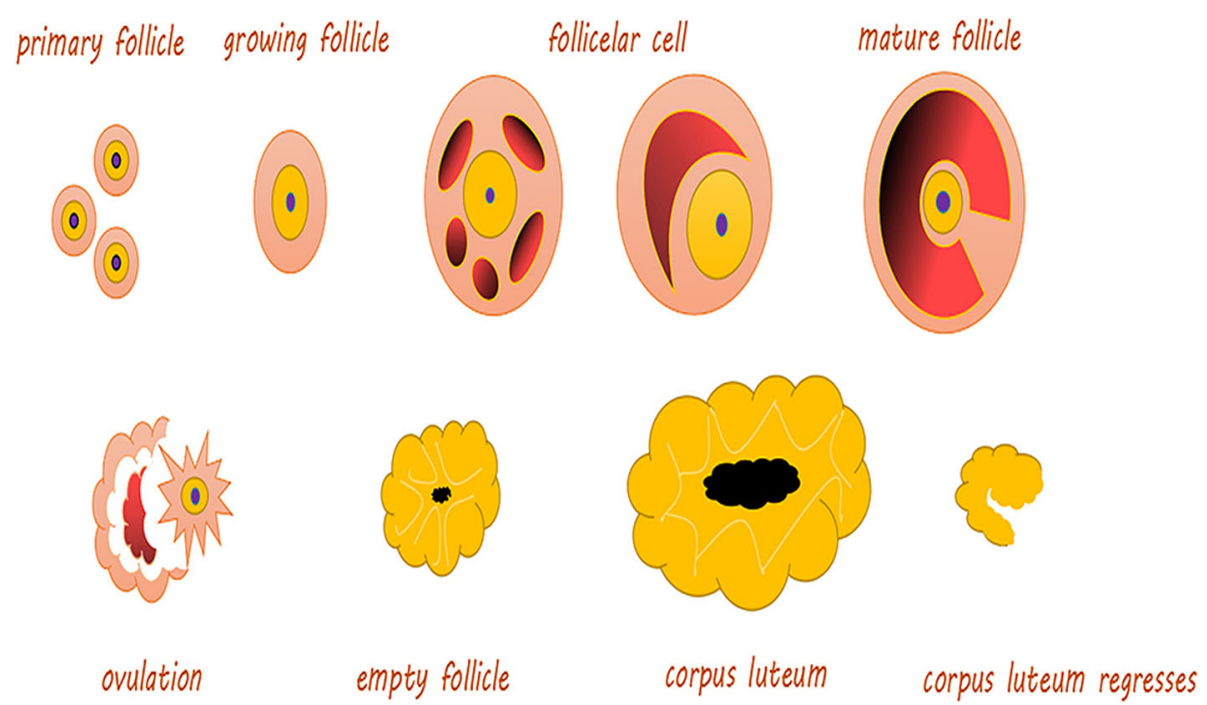

Fig. 1 The development of ovarian follicles. Primary follicle: The center has an oocyte, and there is a flat layer of follicular cells on its periphery. Growing follicle: Including the primary growth follicle and secondary growth follicles. Primary growth follicle: One or more layers of cuboidal follicular cells between the egg cells, and follicular cells demonstrate red-stained zona pellucida, while the follicular periphery appears like connective tissue follicular membrane. Secondary growth follicle: Follicular cells appear in the follicular cavity, and some follicular cavities are large, forming a cumulus of oophores. Follicular cells are located on the inner wall of follicles and are arranged in layers, called granular layers. The follicular membrane includes the inner and outer membrane layers. Mature follicle: The follicle cavity is very large, and cumulus oophores are obvious. Follicular endometrial cells appear close to the follicular granule layer. There is a layer of basement membrane between the granule layer cells and follicular endometrial cells; endometrial cells are polygonal, with clear cytoplasm and round nuclei; cells can be seen between many capillaries, and outer membrane cells are located in the outermost layer, mostly spindle shaped with the surrounding connective tissue boundaries not obvious. Ovulation: Mature follicles develop to a certain stage, obviously protruding from the ovarian surface; with the follicular fluid increasing sharply, the pressure increases so that the prominent part of the ovarian tissue becomes thinner and finally ruptures; secondary oocytes and their peripheral zona pellucida and radiation crowns are discharged together with the follicular fluid. Empty follicle: At this time, the follicle is empty, indicating that the corpus luteum starts to form. Corpus luteum: The residual follicle wall collapses after ovulation; the connective tissue of the follicular membrane and capillaries stretches into the particle layer, and as the role of LH evolves, it evolves into a larger volume cell cluster, rich in capillaries and endocrine function and fresh yellow in color

[20]. GSR is a cytosolic protein with a tissue distribution similar to that of GPx. The enzyme reduces oxidized glutathione, utilizing NADPH generated by various systems (reaction 8) [21].

$$
\begin{aligned}
& 2 \mathrm{H}_{2} \mathrm{O}_{2} \rightarrow 2 \mathrm{H}_{2} \mathrm{O}+\mathrm{O}_{2} \\
& \mathrm{H}_{2} \mathrm{O}_{2}+2 \mathrm{GSH} \rightarrow \mathrm{GSSG}+2 \mathrm{H}_{2} \mathrm{O} \\
& \mathrm{ROOH}+2 \mathrm{GSH} \rightarrow \mathrm{GSSG}+\mathrm{ROH}+\mathrm{H}_{2} \mathrm{O} \\
& \mathrm{GSSG}+\mathrm{NADPH}+\mathrm{H}^{+} \rightarrow 2 \mathrm{GSH}+\mathrm{NADP}^{+}
\end{aligned}
$$

\section{Secondary defense}

The existence has been reported of an enzyme with peroxidase activity called phospholipid hydroperoxidase GPx, which is capable of reducing lipid hydroperoxides without the action of phospholipase A2 [22]. In addition, different oxidoreductases that catalyze reduction reactions of thiol and other protein groups when these molecules are oxidatively damaged are protective enzymes against oxygen free radicals. Nuclear enzymes for DNA repair are considered to be defense systems against oxidative injury by oxygen free radicals [23]. Vitamin E, the major lipid-soluble antioxidant present in all cellular membranes, protects against lipid peroxidation. The tocopheryl radical might also be directly reduced by the ascorbic acid-GSH redox couple. $\beta$-carotene exerts the most efficient scavenger action with vitamin $E$, while $\beta$-carotene acts at low oxygen pressures. However, vitamin E protects conjugated double bonds of $\beta$-carotene from oxidation.

In all, OS plays an important role in the pathophysiology of complicated pregnancies. OS was described as an imbalance in the generation of ROS [1]. These ROS are oxygen free radicals produced by the reduction in molecular oxygen and generated as byproducts of aerobic respiration and metabolism. These molecules are capable of activating and modulating various signaling pathways, including those involved in cell growth, differentiation and metabolism [24]. They can also induce cellular oxidative damage by interacting with DNA and intracellular macromolecules, such as protein and membrane lipids, so they can lead to cellular malfunction that can initiate pathological processes. 


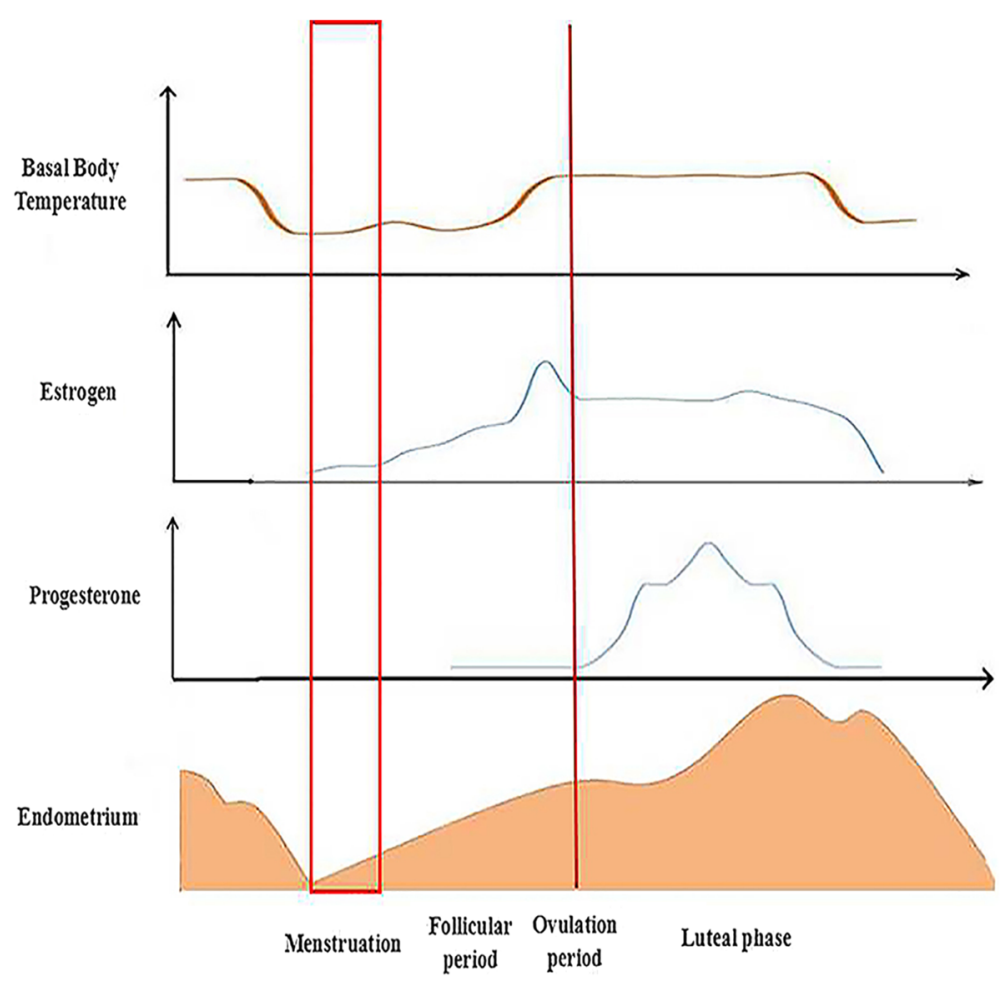

Fig. 2 The changes of biology during different estrus cycle. Estrogen and progesterone are secreted via the ovary or uterus and undergo changes during the estrus cycle. In addition, the basal body temperature also changes, while the thickness of the endometrium has corresponding transformations. After menstruation, the new estrus cycle starts to develop. During the follicular period, the level of the basal body temperature and estrogen gradually rise. The thickness of the endometrium also increases. The levels of basal body temperature and estrogen maintain certain concentrations until the ovulation period. Thus, progesterone starts to increase. With the appearance of the luteal phase, all changes are restored until the end of menstruation
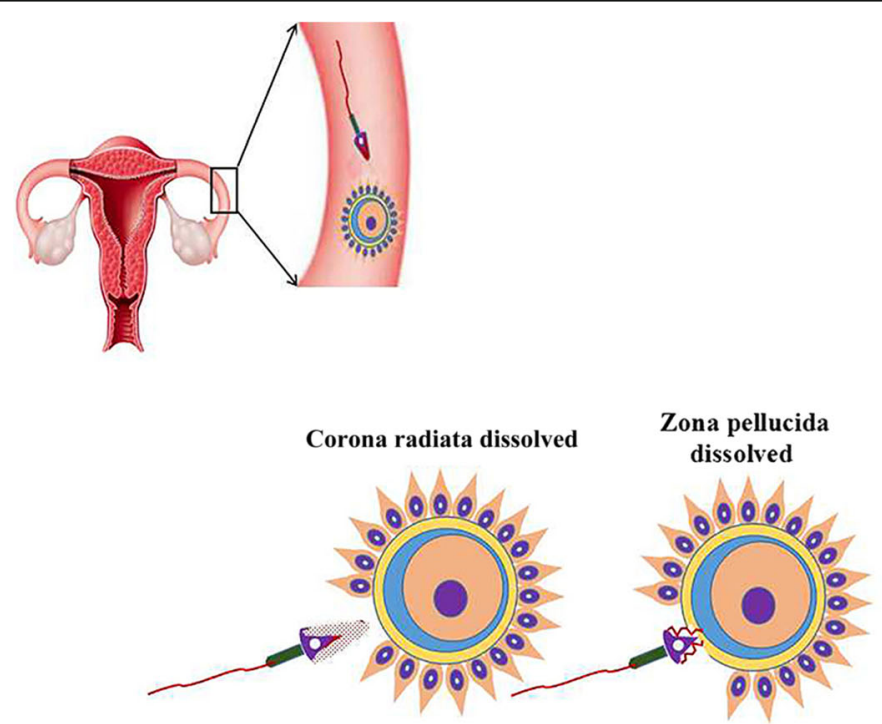

Egg fertilization and cortical reaction

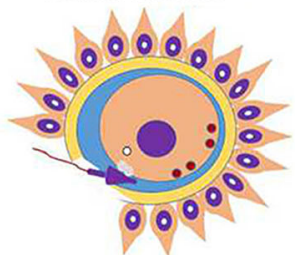

Fig. 3 Fertilization processes of most viviparous and ovoviviparous animals. In most viviparous and ovoviviparous animals, the sperm and oocyte combine at the fallopian tube ampulla. In the picture, the first zygote shows a radiation crown dissolving; the second zygote shows the zona pellucida dissolving; the last zygote shows fertilized eggs and cortical response 


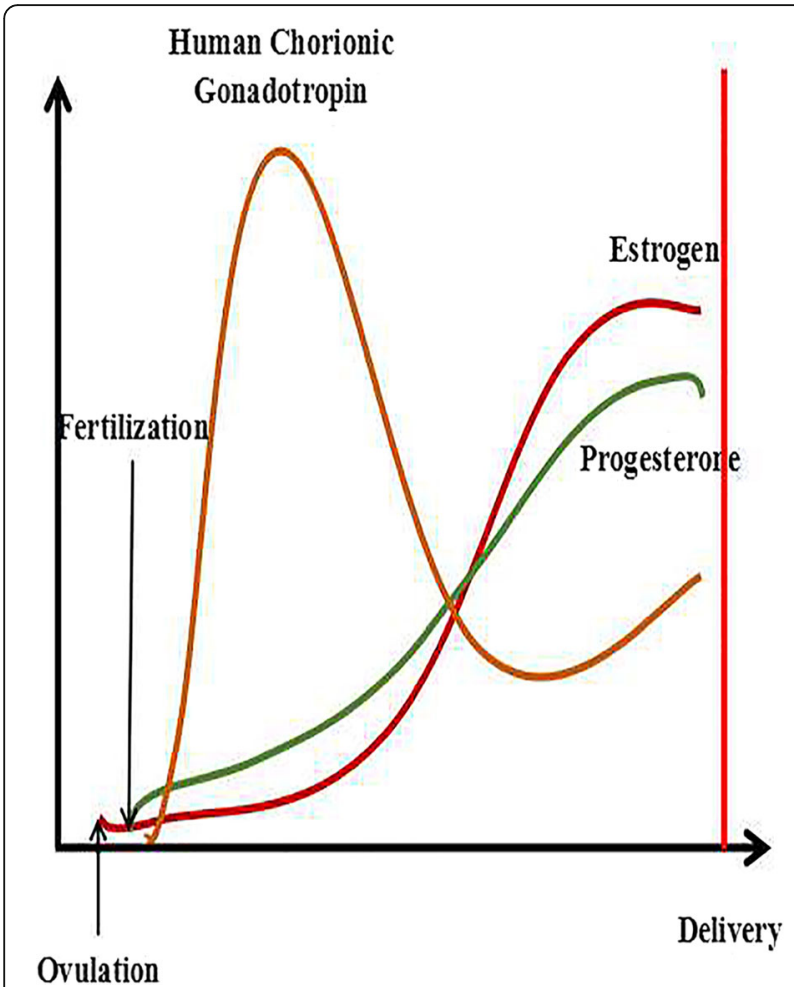

Fig. 4 The trends of HCG, estrogen and progesterone during pregnancy. The yellow line represents the change in HCG. The green line represents the change in progesterone. The red line represents the level of estrogen. The final results of ovulation include two impacts, one of which is output in the body, called menstruation, and the other of which is combines with sperm, called fertilization. The level of hormones changes after fertilization; in particular, hCG immediately increases to the highest level. However, the levels of estrogen and progesterone slowly increase to stable concentrations, while hCG begins to drop to a certain extent

\section{Oxidative stress in ovary}

ROS affect a variety of physiologic functions of the ovary, including ovarian steroid genesis, oocyte maturation, ovulation, formation of blastocysts, implantation, luteolysis and luteal maintenance in pregnancy. OS is an important modulator of ovarian germ cell and stromal cell physiology [25]. Concentrations of ROS could also play a major role in the implantation and fertilization of eggs, and a relevant study showed localization of SOD in the ovary and found that copper-zinc SOD (Cu-Zn SOD) was localized in the granulose cell of growing follicles and mature Graafian follicles, as well as manganese superoxide dismutase (MnSOD) being localized in luteal cells of the corpus luteum in rats [26].

ROS exert both negative and positive effects on mammalian ovaries [27]. ROS affect multiple physiological and pathological activities in the ovaries, from oocyte maturation to fertilization. In cycling ovaries, different markers of OS are negatively affected [28, 29]. Macrophages, leukocytes, and cytokines present in the follicular fluid microenvironment are major sources of ROS. ROS in the follicular fluid join in follicular growth, oocyte maturation, and ovarian steroid biosynthesis [15]. At the same time, a critical process for ovarian folliculogenesis, dominant follicle selection, CL formation and embryo formation is angiogenesis [30, 31], which is a complex process. It is promoted by estrogens that regulates some cellular factors, such as VEGF [32]. ROS produced from $\operatorname{NADP}(\mathrm{H})$ oxidase were shown to be significant for angiogenesis in vivo and VEGF signaling in vitro [33]. Accordingly, ROS are involved in follicular growth in part by regulating angiogenesis.

The appropriate amount of ROS is required for ovulation. ROS produced by the preovulatory follicle are considered critical inducers of ovulation, and inhibition of ROS has been confirmed to disturb ovulation [27, 34]. Oxygen deprivation stimulates follicular angiogenesis, which is important for abundant growth and development of ovarian follicles [35]. The development of follicles from the primordial stage to antral follicles is accompanied by a marked increase in the metabolic function of granulosa cells, especially a large increase in cytochrome P450 activity with steroid biosynthesis [36]. Large amounts of ROS are produced during electron transport, indicating that functional granulosa cells are related to the pro-oxidant state in the follicles. ROS are induced in preovulatory follicles with oscillation of prostaglandins, cytokines, proteolytic enzymes, and steroids, resulting in blood flow alterations and eventual follicle rupture [37]. With the exception of dominant follicles, which are released for fertilization, the other growing follicles all undergo apoptosis, and this process is promoted by ROS. In parallel, follicle-stimulating hormone (FSH)-induced estrogen synthesis and upregulation of CAT and GSH in growing follicles resist the apoptotic process to maintain the balance during normal ovarian function [38]. ROS are generated in the CL and are involved in functional luteolysis. ROS and antioxidants are related to progesterone synthesis in the luteal phase [35] (Table 1).

However, excessive deprivation of oxygen will also cause some damage to follicles, as we discuss in the following. $\mathrm{Cu} / \mathrm{Zn}-\mathrm{SOD}$ is increased in the $\mathrm{CL}$ during the early to mid-luteal phase, but it is decreased during the regression phase, which could explain the increase in ROS concentrations during regression, and this change in activity is similar to that in progesterone concentrations. Other possible explanation for the decrease in $\mathrm{Cu}-\mathrm{Zn}$ SOD during the regression phase is an increase in prostaglandin $\mathrm{PGF}_{2 \alpha}$ or macrophages; another reliable explanation is a decrease in ovarian blood flow [35]. Prostaglandin $\mathrm{F}_{2 \alpha}$ stimulates production of the $\mathrm{SO}$ anion by luteal cells and phagocytic leukocytes in the CL. The reduction of ovarian blood flow causes tissue damage by 


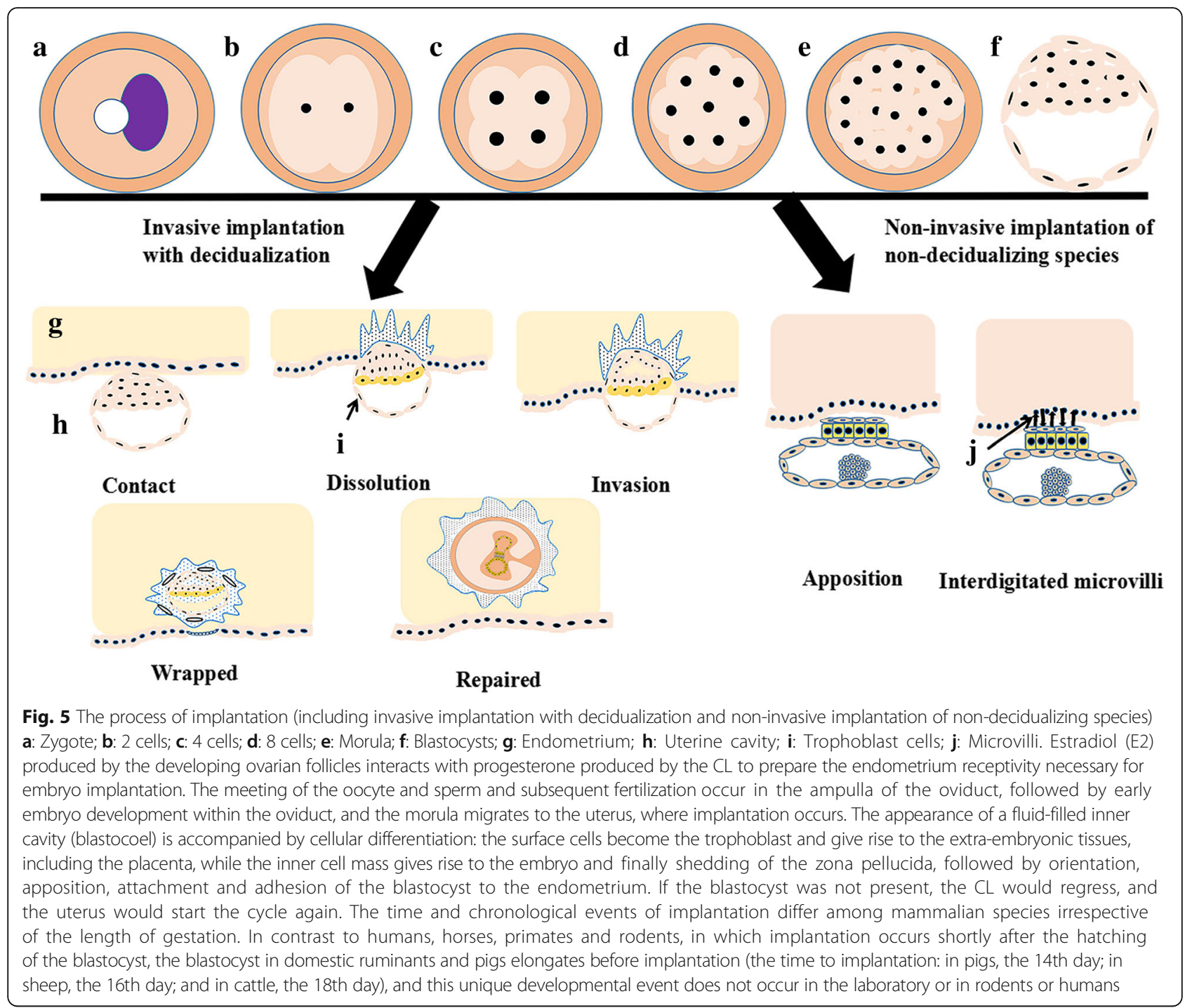

ROS production. However, the concentration of $\mathrm{Mn}-\mathrm{SOD}$ in the CL during regression is increased, thus scavenging the ROS produced in the mitochondria by inflammatory reactions and cytokines. Therefore, complete disruption of the CL leads to a significant decrease in Mn-SOD in the regressed cells, and cell death is imminent [39]. In addition, ROS also participate in mammalian ovulation and follicular rupture. The generation of the two processes is the result of vascular changes or the proteolytic cascade. The crosstalk between these two cascades is mediated by ROS, cytokines, and vascular endothelial growth factor (VEGF) [40, 41]. Ad4BP, a zinc finger DNA-binding protein, was identified as a transcription factor regulating steroidogenic P-450 genes in a cAMP-dependent manner [42], and a recent study showed that the correlation between Ad4BP and SOD expression suggested an association between OS and ovarian steroid genesis. Both human granulosa and luteal cells respond to hydrogen peroxide with extirpation of gonadotropin action and inhibition of progesterone secretion. Hydrogen peroxide lowers both cAMP-dependent and non-cAMP-dependent steroidogenesis $[28,43]$. As we all know, OS influences the entire reproductive process of women's lives. ROS attacks the 8th carbon atom of guanine in DNA to generate 8-hydroxy-deoxyguanosine (8-OHDG), which is an oxidized derivative of deoxyguanosine, the levels of which are higher in aging oocytes [44]. 8-OHdG is the most familiar base modification in mutagenic damage. 8-OHdG causes base mutation and mismatches in DNA replication, resulting in $\mathrm{G}$ mutations to $\mathrm{T}$ and $\mathrm{G}: \mathrm{C}$ to T:A transversion. Therefore, 8-OHdG has become a marker for OS.

OS has been implicated in different female diseases, including PCOS, which is the most common endocrine abnormality of reproductive-aged women and has a prevalence of approximately $18 \%$. It is a disorder 


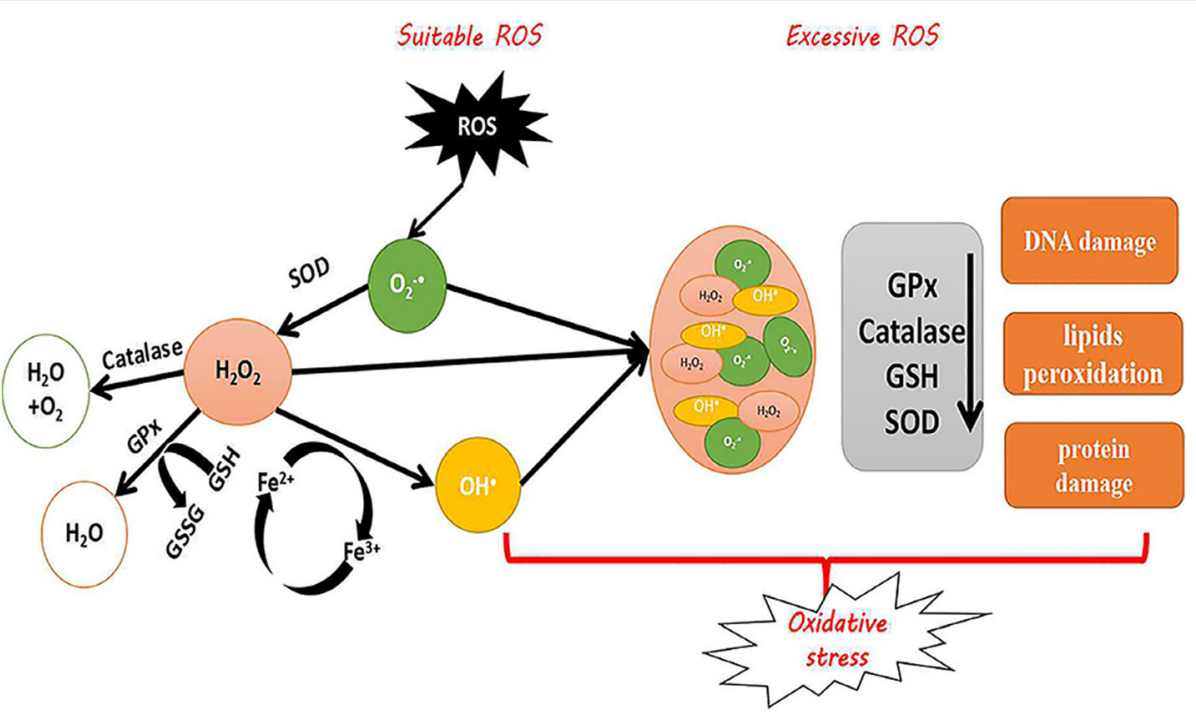

Fig. 6 The defense mechanism against oxygen free radicals. SOD: Superoxide dismutase; GPx: Glutathione peroxidase; GSSG: Glutathione oxidase; GSH: Glutathione reductase; ROS: Reactive oxygen species; $\mathrm{O}_{2}{ }^{-} \cdot$ Superoxide; $\mathrm{H}_{2} \mathrm{O}_{2}$ : Hydrogen peroxide; $\cdot \mathrm{OH}$ : Hydroxyl

characterized by hyperandrogenism, ovulatory dysfunction, and polycystic ovaries [45]. Various studies have reflected the presence of OS in PCOS patients. In a study by Hilali et al., PCOS patients had increased serum prolidase activity, as well as higher total oxidant status and OS indices-the ratio of oxidants to total antioxidant status. The decrease in mitochondrial $\mathrm{O}_{2}$ consumption and GSH levels, along with increased ROS production, explains the mitochondrial dysfunction in PCOS patients. Physiological hyperglycemia generates increased levels of ROS from mononuclear cells, which activate the release of tumor necrosis factor- $\alpha$ (TNF- $\alpha$ )

Table 1 The role of oxidative stress in the female reproductive process

\begin{tabular}{|c|c|c|}
\hline Function & Reproductive process & Reference \\
\hline \multirow[t]{6}{*}{ Positive effect } & Zn-Cu SOD $\uparrow \rightarrow$ Promotion of the development of follicles & {$[26]$} \\
\hline & $\begin{array}{l}\text { Biosynthesis of ovarian steroids } \rightarrow \mathrm{P} 450 \uparrow \rightarrow \mathrm{ROS} \uparrow \rightarrow \text { Blood flow } \uparrow \rightarrow \text { Rupture of } \\
\text { follicles } \rightarrow \text { Ovulation }\end{array}$ & {$[36,37,40,41]$} \\
\hline & $\begin{array}{l}\text { ROS } \uparrow \rightarrow \text { Promotion apoptosis of non-dominant follicles } \\
\mathrm{FSH} \uparrow \rightarrow \mathrm{E} 2 \uparrow \rightarrow \mathrm{CAT} \text { and GSH} \uparrow \rightarrow \text { Protection of cells from apoptosis }\end{array}$ & {$[38]$} \\
\hline & $\mathrm{E} 2$ and $\mathrm{P} \downarrow \rightarrow \mathrm{SOD} \downarrow \rightarrow \mathrm{OS} \uparrow \rightarrow$ Endometrial shedding and implant failure & {$[62]$} \\
\hline & $\mathrm{ROS} \uparrow \rightarrow \mathrm{NF}-\mathrm{KB} \uparrow \rightarrow \mathrm{PGF}_{2 a} \uparrow \rightarrow$ Luteum dissolution & {$[35,39,61]$} \\
\hline & $\begin{array}{l}\text { Sperm-ovum binding } \rightarrow \text { ROS } \uparrow \rightarrow \text { Corpus luteus functional } \uparrow \\
\text { ROS } \uparrow \rightarrow \text { Antioxidants } \uparrow \rightarrow \text { Synthesis of progesterone }\end{array}$ & [39] \\
\hline \multirow[t]{3}{*}{ Negative effect } & $\begin{array}{l}\text { PCOS: } \\
\text { Serum proline activity } \uparrow, \text { OS } \uparrow \\
\text { Physiological hyperglycemia } \rightarrow \text { ROS } \uparrow \text { (Monocytes) } \rightarrow \text { TNF- } \uparrow \uparrow \rightarrow \mathrm{NF}-\mathrm{kB} \uparrow \rightarrow \text { Resistance of Insulin } \uparrow\end{array}$ & {$[45,46]$} \\
\hline & $\begin{array}{l}\text { Preeclampsia: } \\
\text { Defective placenta } \rightarrow \text { Hypoxia and reperfusion injury } \rightarrow \text { OS } \uparrow \rightarrow \text { Cytokines } \uparrow, \\
\text { Prostaglandins } \uparrow \rightarrow \text { TAS } \downarrow \text {, GPx of placenta } \downarrow \\
V_{C} \downarrow \rightarrow \text { Risk of preeclampsia } \uparrow \\
(\mathrm{MDA} \uparrow) \text { ROS } \uparrow \rightarrow \text { Vasoconstriction } \uparrow \rightarrow \text { Coagulation activity } \downarrow \\
\mathrm{OS} \uparrow \rightarrow \text { Vascular endothelial injury } \uparrow \rightarrow \mathrm{ROS} \uparrow \rightarrow \text { TNF- } \mathrm{A} \uparrow, \mathrm{OX}-\mathrm{LDL} \uparrow \rightarrow \text { Endothelial subtypes of } \\
\text { activated NAD(P)H oxidase } \rightarrow \text { SO anion } \uparrow \\
\text { Auto-antibodies of AT1-AA } \uparrow \rightarrow \mathrm{NAD}(\mathrm{P}) \mathrm{H} \text { oxidase } \uparrow \rightarrow \mathrm{ROS} \uparrow \rightarrow \text { SO anion } \uparrow\end{array}$ & {$[67,76-81,83-85]$} \\
\hline & 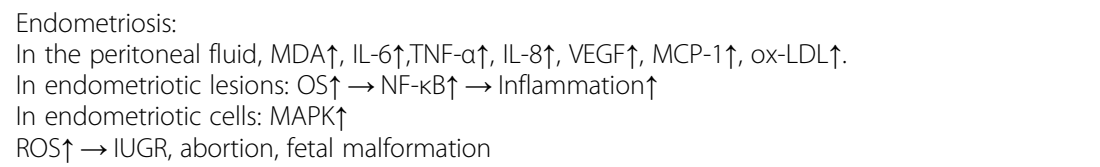 & {$[71-73,75]$} \\
\hline
\end{tabular}


and increase the inflammatory transcription factor nuclear factor-kappa B (NF-KB). As a result, concentrations of TNF- $\alpha$, a known mediator of insulin resistance, are further increased. The resultant OS creates an inflammatory environment that further increases insulin resistance [46], causing abnormal ovarian extracellular remodeling, multiple cyst formation, and chronic anovulation, leading to infertility [47] (Table 1).

Recently, PCOS has been paid significant attention because it exerts severe effects on female reproduction. In this review, we collect some interesting evidence that implies a delicate relationship between stress and PCOS [48]. Its etio-pathogenesis and pathophysiology include roles for genetic, environmental and endocrine factors. Franks et al. defined PCOS as a gene-dependent ovarian pathology, characterized by the overproduction of androgens and not uniformly represented by the interaction of genetic "propensities" with other genetic and environmental factors [49]. Thus, PCOS seems to be a genetic disease, but after investigation by Escobar-Morreale HF et al. found that it is caused by the interaction of susceptibility and protective genetic variants, and these mutations could be chosen due to survival advantages in the evolution process, requiring an accurate study of environmental factors, including race, diet and lifestyle [50]. V. De Leo et al. reported that disruption of the delicate balance between intra-ovarian and extraovarian factors alters and impairs the formation of mature oocytes, leading to infertility. In addition, insulin plays a particular role in PCOS, and in vitro studies have demonstrated that insulin stimulates thecal cell proliferation, increases secretion of androgens mediated by $\mathrm{LH}$ and increases cytochrome $\mathrm{P} 450$ expression of $\mathrm{LH}$ and IGF-1 receptor [51]. As we all know, P450 can increase ROS. The above evidence indicates that ROS join in the pathological process of PCOS.

\section{Oxidative stress in the uterus and placenta}

Pregnancy itself is a state of OS, arising from the increased metabolic activity in the placental mitochondria and increased ROS production due to the higher metabolic demand of the growing fetus [52, 53]. Superoxide (SO) anions produced by the placental mitochondria appear to be a major source of ROS and lipid per-oxidation contributing to OS in the placenta [54], supported by mitochondrial production of lipid peroxides, free radicals, and vitamin $\mathrm{E}$ in the placenta, which increases as gestation progresses[55]. In the second trimester, the placenta gradually matures and increases in size, with less hairiness and wider blood vessels. The cytotrophoblast becomes a single cell and gradually replaces the endothelial layer covering the smooth muscle of the spiral artery. Slowly, maternal blood penetrates from the mother's spiral artery into the interstitial space
[55-57]. During this process, placental tissue forms a large amount of free radicals, and oxidation occurs. Intense stress results, but the placenta gradually adapts to this environment and returns to normal under the action of antioxidant activity [58, 59]. While physiological concentrations of endogenous glucocorticoids are supportive of fetal development, excessive glucocorticoids in utero (i.e., maternal stress) adversely affect mammalian offspring by "programming" abnormalities that are primarily manifested postpartum [60]. ROS are also believed to play a role in the different phases of the endometrial cycle. The late luteal phase is characterized by elevated levels of lipid peroxide and a decrease in the antioxidant SOD. ROS stimulate the secretion of $\mathrm{PGF}_{2 \alpha}$ through activation of NF-kB [61]. Decreased levels of estrogen and progesterone lead to decreased SOD expression and hence generate OS in the uterus, resulting ultimately in endometrial shedding and lack of implantation. Controlled levels of ROS have, however, been associated with angiogenic activity in the endometrium, causing regeneration during every cycle. These studies showed that limited levels of ROS are necessary to maintain physiological function, but when present in higher concentrations, ROS can have deleterious effects [62]. In other words, although a physiological balance between ROS and antioxidant activity is maintained in normal pregnancies [63], an imbalance can increase OS. The placenta experiences a heightened level of OS in certain pathologic conditions of pregnancies, including gestational diabetes, fetal growth restriction, preeclampsia and miscarriage [64-66].

OS leads to endothelial cell dysfunction. In the uterus, endothelial cell dysfunction results in many diseases, such as preeclampsia and endometriosis. There are many causes that induced endothelial cell dysfunction. TNF- $\alpha$, a plasma cytokine, has been demonstrated to cause endothelial cell injury, but the antioxidant $\mathrm{Mn}$-SOD neutralizes $\mathrm{SO}$ anions generated by the cytokine TNF- $\alpha$. This process is a self-protective mechanism against TNF- $\alpha$-induced OS. In addition, defective placentation leads to placental hypoxia and reperfusion injury due to ischemia, and the resultant OS triggers the release of cytokines and prostaglandins, resulting in endothelial cell dysfunction and playing an important role in the development of preeclampsia [67]. In addition, ROS generated from NADP $(\mathrm{H})$ oxidase are critical for VEGF signaling in vitro and angiogenesis in vivo [33]. Small amounts of ROS are produced from endothelial NADP $(\mathrm{H})$ oxidase activated by growth factors and cytokines. ROS generated in and around the vascular endothelium could play a role in normal cellular signaling mechanisms. They might also be important causative factors in endothelial dysfunction. 
Endometriosis is a benign, estrogen-dependent, chronic gynecological disorder characterized by the presence of endometrial tissue outside the uterus. There was a report suggested that the elevated ROS causing OS are produced by erythrocytes and apoptotic endometrioma cells, as well as the activated macrophages that are recruited to phagocytize apoptotic cells [10]. Additionally, the ROS producing enzyme xanthine oxidase, which is considered another contributor to excess ROS, are expressed in greater quantities in women with endometriosis [68]. OS plays a large role in infertility. Another way in which cells are damaged through OS is via lipid peroxidation, which is the oxidative destruction of polyunsaturated fatty acids in the plasma membrane [69]. This leads to "increased membrane permeability, degraded membrane integrity, inactivated enzymes and structural damage of the DNA; cell death rapidly follows" [70]. In addition, OS induces local inflammation, resulting in elevated levels of cytokines and other factors that promote endometriosis, as discussed later [8].

The peritoneal fluid of patients has been found to contain high concentrations of malondialdehyde (MDA), pro-inflammatory cytokines (IL-6, TNF- $\alpha$, and IL-1 $\beta$ ), angiogenic factors (IL-8 and VEGF), monocyte chemoattractant protein-1 (MCP-1) [71], and oxidized LDL (ox-LDL). Pro-inflammatory and chemotactic cytokines play central roles in the recruitment and activation of phagocytic cells, which are the main producers of ROS and RNS. Activation of NF- $\mathrm{KB}$ by OS has been detected in the endometriotic lesions and peritoneal macrophages of patients with endometriosis [72]. Signaling mediated by NF-kB stimulates inflammation, invasion, angiogenesis, and cell proliferation, and it also promotes the apoptosis of endometriotic cells. Additionally, $\mathrm{N}$-acetylcysteine (NAC) and vitamin E are antioxidants that limit the proliferation of endometriotic cells, likely by inhibiting activation of NF-kB [73]. A study indicated a therapeutic effect of NAC and vitamin E supplementation on endometriotic growth [74]. Similar to tumor cells, increased ROS and subsequent cellular proliferation in endometriotic cells activate of mitogen-activated protein kinase (MAPK) and extracellular regulated kinase (ERK1/2) [75]. More seriously, the increase in ROS in endometriosis patients can lead to adverse effects on embryos, such as IUGR, spontaneous abortion, or fetal dysmorphogenesis [69] (Table 1).

Preeclampsia is a vascular pregnancy disorder that often involves impaired placental development. It is a complex multisystem disorder that can affect normotensive women. It can cause the poor implantation and growth restriction observed in preeclampsia because OS causes increased nitration of p38 MAPK, resulting in a reduction in its catalytic activity.
Increased ROS concentrations in patients with preeclampsia have been proved by the increased levels of MDA, an index of lipid peroxidation [76]. Under normal conditions, the impairment of circulatory homeostasis is caused chiefly by vascular endothelial dysfunction in preeclampsia. It is characterized by the tendency to cause vasoconstriction and low anticoagulant activity. ROS seem to play a critical role in the endothelial dysfunction associated with preeclampsia [77]. In other words, the pathologic event in preeclampsia is injury to the vascular endothelium regulated by OS from increased placental ROS [78] or decreased antioxidant activity [79].

There are many reasons for the increase in ROS. For instance, neutrophil modulation occurring in preeclampsia is an important source of ROS, resulting in increased production of the $\mathrm{SO}$ anion and decreased levels of $\mathrm{NO}$, ultimately causing endothelial cell damage in patients with preeclampsia. Levels of TNF- $\alpha$ and oxLDL are increased in preeclampsia and have been shown to activate the endothelial isoform of $\mathrm{NAD}(\mathrm{P}) \mathrm{H}$ oxidase, ultimately resulting in increased levels of the $\mathrm{SO}$ anion. These results suggest that the consumption of antioxidants to counteract heightened lipid per-oxidation might injure the vascular endothelium and could be involved in the pathogenesis of preeclampsia [80].

In addition, autoantibodies against the angiotensin receptor AT1, particularly the second loop (AT1-AA), can stimulate $\mathrm{NAD}(\mathrm{P}) \mathrm{H}$ oxidase, leading to increased generation of ROS [81]. The AT1 receptor of preeclamptic women has been observed to promote both the generation of the $\mathrm{SO}$ anion and over-expression of NAD $(\mathrm{P}) \mathrm{H}$ oxidase in cultured trophoblasts and smooth muscle cells. Therefore, early placental development can be affected by dysregulated vascular development and function secondary to $\mathrm{NAD}(\mathrm{P}) \mathrm{H}$ oxidase-mediated altered gene expression [82]. Preeclamptic women produce ROS and exhibit higher $\mathrm{NAD}(\mathrm{P}) \mathrm{H}$ expression than those without the disease [35]. More specifically, it has been reported that women with early-onset preeclampsia produce larger amounts of the SO anion than women with late-onset disease [83]. Affected women also have decreased total antioxidant status (TAS) and placental GPx [84] and low levels of vitamins C and E. Lack of vitamin $\mathrm{C}$ intake seems to be associated with an increased risk of preeclampsia, and some studies have shown that periconceptional supplementation with multivitamins can lower the risk of preeclampsia in normal or underweight women [85].

There have been studies focusing on the effects of restraint stress on uterine and embryo implantation in pregnant mice. In these studies, uterine local micro-environment changes and uterine histomorphology research were emphasized. Liu Guanhui et al. reported 
that the mice were subjected to restraint stress from embryonic day1 (E1). This study demonstrated that restraint stress increased the level of corticosterone (CORT) in plasma, and uterine natural killer (uNK) cells in the endometrium were significantly increased, accompanied by the decreased density of mast cells in the myometrium. In addition, restraint stress markedly decreased the $\mathrm{CD}^{+} \mathrm{CD}^{+}$ $\mathrm{T} / \mathrm{CD}^{+} \mathrm{CD}^{+} \mathrm{T}$ cell ratio. Additionally, antioxidant ability was compromised, and the concentration of MDA was increased [86]. Moreover, restraint stress reduced the weight of the uterus and ovary and the intake of food with reduction in weight, while the relative endometrial area and uterine gland area were reduced after restraint stress. In addition, restraint stress decreased micro-vessel density and VEGF expression [87].

\section{The signaling molecules between oxidative stress and reproduction}

OS has led to a variety of signaling pathways, resulting in crosstalk among many protein factors in the body. Especially in the female reproductive organs, OS leads to a series of abnormal events in egg production and ovulation. During pregnancy, implantation will be impaired, leading to loss of embryos and changes in local immune function in the uterus. Research on these signals is currently the most important concept in this field and is of great significance to the reproduction of female animals.

Before this review, there were a number of reviews discussing the contact between reproduction and OS. For example, Perucci et al. proposed a hypothesis that the ADAMs pathway protects women from the inflammatory lesions of preeclampsia [88]. Wu et al. elaborated on potential therapeutic approaches to placental stress by exploring the relationship between OS and apoptosis and between OS and cellular autophagy, resulting in speculation about a comprehensive therapeutic target [89]. Sultana et al. fully summarized the adverse pregnancy outcomes caused by aging placentas, explaining the mechanisms of telomerase and placental disorders [59]. Wojsiat et al. explained the effects of OS on oocyte and fertilization outcomes and the effect of overproduction of active substances on in vitro fertilization [90]. Nevertheless, our review not only summarizes the above discussion but also makes reasonable assumptions about the signaling pathways in reproductive diseases.

Hypoxia and inflammation lead to the production of TNF- $\alpha$, which induces the release of large amounts of ROS from the mitochondria in cells. Excessive ROS cause an imbalance between oxidation and antioxidation, leading to OS. The body's signaling pathway will evince a series of changes following to exposure to the dual impact of OS and inflammation. This article focuses on the collection of OS-induced reproductive disease-related signaling pathways, including the p38 MAPK pathway, the Kelch-like ECH-associated protein 1 (Keap1)-Nuclear factor erythroid 2-related factor 2 (Nrf2) pathway, the Jun N-terminal kinase (JNK) pathway, the forkhead transcription factors of the $\mathrm{O}$ class (FOXO) family, and apoptosis.

Nrf2 is a key molecule activated in response to OS, and it regulates antioxidant response to protect cell function [91]. Normally, Nrf2 binds to Keap1, is sequestered in the cytoplasm, and then is degraded by a proteasome pathway [92]. After activation, it transfers to the nucleus to activate a large number of antioxidant genes [93]. In other words, transcriptional activation of antioxidant defense genes and restoration of vascular redox homeostasis are necessary when OS occurs. Importantly, the redox-sensitive Keap1-Nrf2 pathway plays a key role in the process [94]. These studies also implied that Nrf2 deficiency caused fetal DNA damage and neurological deficits, and inactivation of Nrf2 has also been shown to underlie inflammation-induced trophoblastic apoptosis. As studies have progressed, the literature has increasingly revealed that Nrf2 plays a significant role in pregnancy and has highlighted the important role of Nrf2 in protecting the fetus in utero OS [95]. Nrf2 is sensitive to maternal immunological status. In normal pregnancy, Nrf2 is only decreased after term vaginal delivery. However, notably, the expression of Nrf2 is significantly reduced when the uterus is infected [96]. Furthermore, the mechanism of Nrf2 antioxidant defense plays an important role in adverse pregnancy priming. Nrf2 is a regulator of antioxidant defense in vascular dysfunction and oxidative damage [95]. Many studies have shown that suitable OS increased Nrf2 and the expression of downstream targets, such as heme oxygenase $1(\mathrm{HO}-1), \mathrm{NAD}(\mathrm{P}) \mathrm{H}$ : quinoneoxidoreductase (NQO1), and glutamate-cysteine ligase subunit catalysis (GCLC), etc., to resist OS [97]. However, as described above, we speculate that the activity of Nrf2 significantly decreases, and Keap1 binds to Nrf2 more strongly when excessive OS causes severe inflammation in the uterus. Related studies have shown that FOXO3 participates in the interaction between Keap1 and Nrf2. Loss of FOXO3 leads to severe inactivation of Keap1, which in turn cannot prevent the activation of Nrf2, which is a very important finding in tumors. Research also revealed the important role of FOXO3 in the Keap1-Nrf2 axis. At the same time, it is not denied that, in the absence of FOXO3, Nrf2 is activated under the induction of AKT and protects cells from damage due to OS by this form [98]. Therefore, we hypothesize that, if OS induces inflammation in the reproductive system, the changes in FOXO3 affect the interaction between Keap1 and Nrf2, which could be a marker of damaging OS in our study (Table 2).

$\mathrm{NF}-\mathrm{kB}$ is an active molecule in the immune system. In mammals, the NF- $\mathrm{kB}$ family is composed of five related transcription factors: c-Rel, p50, p52, RelB and RelA 


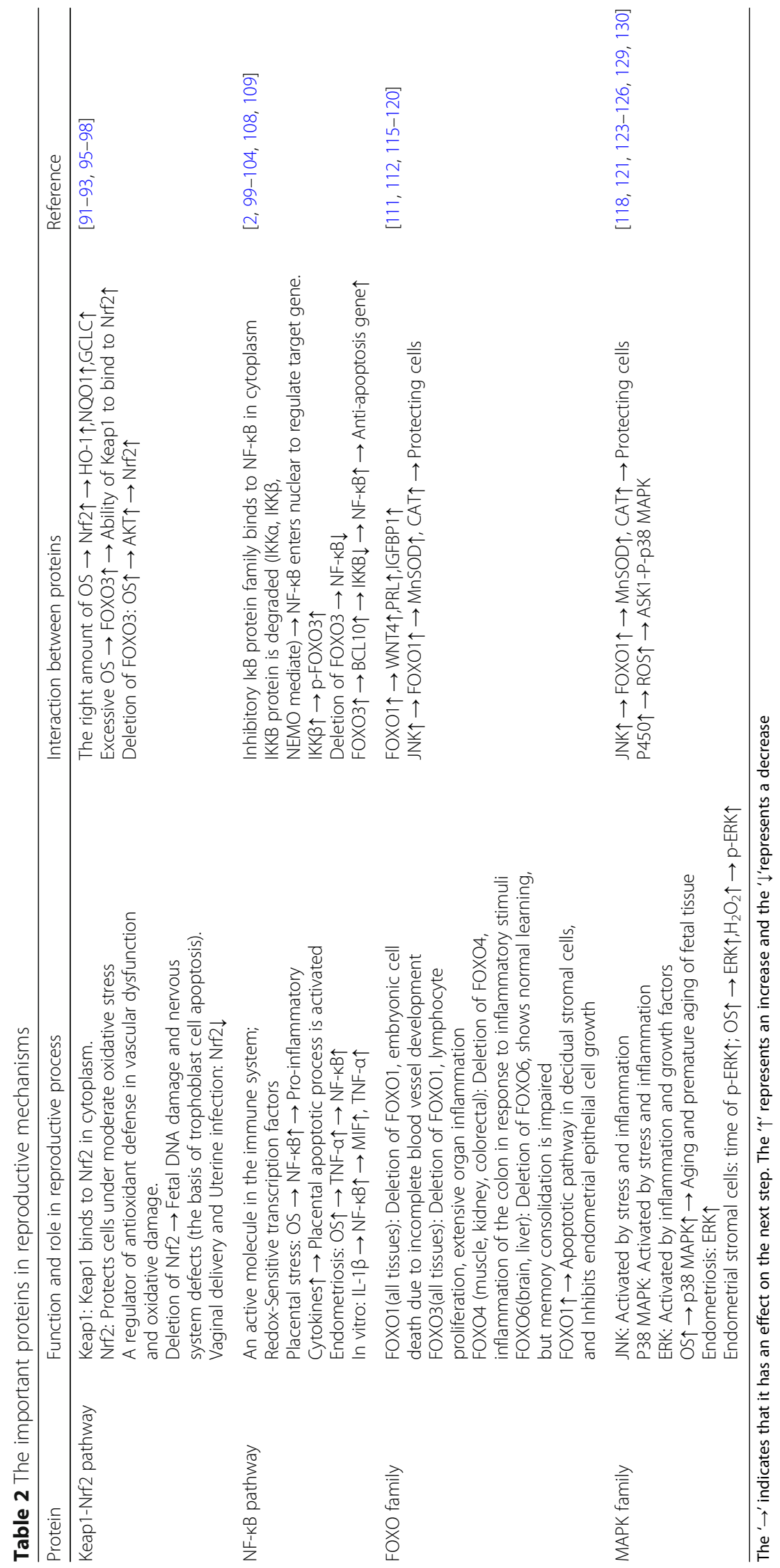


(a.k.a. p65) [99]. NF- $\mathrm{kB}$ is the nodal point of a primary inflammation-stimulated signaling pathway that plays a significant role in the immune response [100], while $\mathrm{NF}-\mathrm{KB}$ is also a redox-sensitive transcription factor [101]. Therefore, its effect is self-evident in OS, including embryonic stresses. The NF- $\mathrm{kB}$ pathway is activated when embryonic stresses occurs, and a variety of pro-inflammatory cytokines is increased. Then, the apoptotic process of the placenta is activated [2]. Therefore, this study indicated that NF-kB controls cell survival through the enhancement of anti-apoptotic gene transcription. In most cells, the NF- $k B$ complex is inactive, and it is mainly present in the cytoplasm by binding to the inhibitory IкB protein family. When the NF- $\mathrm{KB}$ pathway is activated, the I $\mathrm{B}$ protein is degraded, NF- $\mathrm{KB}$ complex enters the nucleus to modulate the expression of target genes, and the degradation of ІкB protein is mediated through the ІкB kinase (IKK) complex, which consists of two catalytically active kinases (IKK $\alpha$ and IKK $\beta$ ) and the regulatory scaffold protein NEMO. In the activation pathway, IKK $\beta$ and NEMO are very necessary for activation of the complex [102], while IKK $\beta$ also acts on other factors, such as Forkhead box O3, a transcription regulator. A study showed that FOXO3 is subject to IKK $\beta$-mediated phosphorylation, leading to the nuclear exclusion and degradation of FOXO3 [103]. In addition, a study reported that FOXO3 was a positive regulator of NF- $\mathrm{kB}$ signaling and found that over-expression of FOXO3 increased and knockdown of FOXO3 repressed NF- $\mathrm{kB}$ activities. The study indicated that FOXO3 activated NF- $\mathrm{KB}$ by inducing expression of B-cell lymphoma/leukemia 10 (BCL10), an upstream regulator of inhibitor of kappa B kinase (IKK)/NF-KB signaling [104]. In reproductive stress diseases, for example, endometriosis, increased expression of NF- $\mathrm{kB}$ has been confirmed in cultured endometriotic stromal cells [105] and peritoneal macrophages isolated from women with endometriomas [106]. In any case, changes in NF- $\mathrm{kB}$ are strongly associated with inflammation. Endometriosis is a disease caused by OS during reproductive. OS leads to an increase in TNF- $\alpha$, which in turn causes inflammation, and the NF- $\mathrm{kB}$ pathway is activated. Additionally, in vitro evidence raised the possibility that the changes might be due to the endometriotic microenvironment. IL-1 $\beta$ stimulates NF- $\mathrm{kB}$ with subsequent increased production of inflammatory cytokines [107], including macrophage migration inhibitory factor (MIF) in endometrial stromal cells [108] and TNF- $\alpha$ in the immortalized epithelial (12Z) cell line [109]. In conclusion, the NF- $\mathrm{KB}$ pathway is activated when reproductive OS occurs (Table 2).

FOXO1, the same family as FOXO3, is also involved in the processes of OS and pregnancy. The FOXO subfamily of Forkhead transcription factors is a direct downstream target of the PI3K/Akt pathway [110]. The mammalian forkhead transcription factors of the $\mathrm{O}$ class
(FOXOs) number four: FOXO1, FOXO3, FOXO4, and FOXO6. Further, FOXO1 and FOXO3 exist in nearly all tissues. FOXO4 is highly expressed in the muscle and kidneys, and FOXO6 is primarily expressed in the brain and liver. They are involved in the processes of proliferation, apoptosis, autophagy, metabolism, inflammation, differentiation and stress tolerance [111]. However, FOXO1 plays a significant role in reproduction. It regulates cyclic differentiation and apoptosis in the normal endometrium [112]. Additionally, genome-wide expression profiling demonstrated that FOXO1 knockdown perturbs the expression of more than 500 types of genes in decidualizing human endometrial stromal cells [113]. In the past, many studies of human endometrium provided reliable evidence for this ability of FOXO transcription factors to regulate diverse genes in response to change hormones [114]. However, the interaction between progesterone and FOXO1 is even more striking. It is well known that progesterone exerts inhibitory effects on endometrial epithelial growth, and a study revealed this mechanism and showed that siRNA inhibition of FOXO1 significantly attenuated the effects of progestin in inhibiting endometrial epithelial cell growth. Therefore, FOXO1 is essential for the anti-proliferative effects of progesterone on both endometrial stromal and epithelial cells [115].

Further, FOXO1 is indispensable for the induction of the most highly responsive decidual marker genes, including WNT4, prolactin (PRL) and insulin-like growth factor-binding protein 1 (IGFBP1) [116]. It has been found that FOXO1 activates apoptotic pathways in decidual stromal cells. The pro-apoptotic Bcl-2 homology 3 domain-only protein BIM is a major intermediate in this pathway [117]. It was validated that BIM is a FOXO1 target gene and is induced under the stimulation of cAMP. Both cAMP and progestin promote increases in FOXO1, but BIM is only increased and cell death occurs when progestin disappears [120]. Additionally, targeted phosphorylation of cytoplasmic FOXO factors by JNK promotes nuclear import and increases cellular protection against OS via the transcriptional activation of MnSOD and CAT [118]. Thus, FOXO1 has emerged as a major regulator of progesterone-dependent differentiation of human endometrium and subsequent process (Fig. 7) [119]. Thoughtfully, FOXO1 is markedly induced upon decidualization both in vivo and in vitro, whereas FOXO3 expression is suppressed [120]. At any rate, FOXO1 plays a unique role either in reproduction or in OS (Table 2).

The extracellular environment activates three pathways, with ERK predominantly activated by inflammation and growth factors, while JNK and p38 MAPK are predominantly activated by stress and inflammation [121]. Additionally, studies by Lee et al. showed that ROS generated by dysfunctional electron transport in 


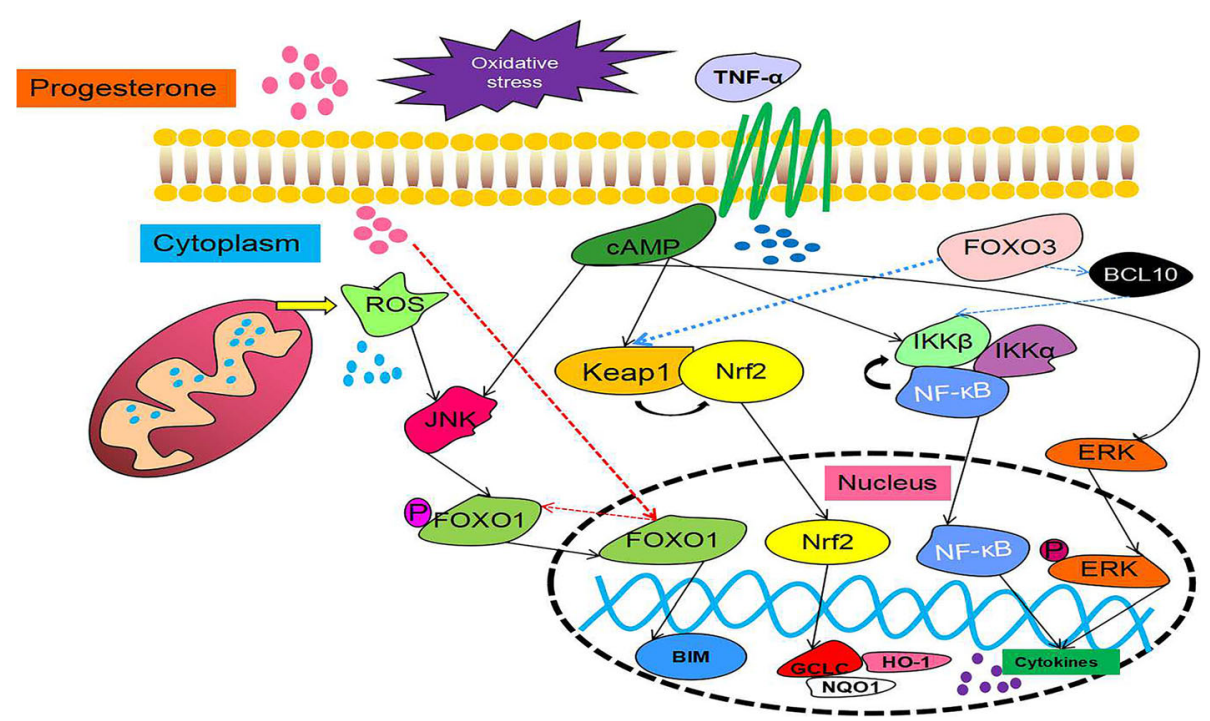

Fig. 7 The signaling pathway of OS and pregnancy (a brief view). When the body, especially the maternal body, suffers from an imbalance between oxidation and antioxidant levels during pregnancy, in addition to changes in TNF-a, changes in progesterone cannot be ignored. First, TNF-a activates a series of signaling pathways in cells through CAMP, such as stimulation of the Keap1-Nrf2 signaling pathway, NF-KB signaling pathway, MAPK signaling pathway, etc., then promoting an increase in cytokines and changes in antioxidant-related genes. However, FOXO3 is involved in these signaling pathways. When FOXO3 is increased, it promotes the binding of Keap1-Nrf2, lowering the level of antioxidants and promoting the release of NF-KB by IKKB by stimulating $\mathrm{BCL} 10$, thereby promoting the increase in cytokines and apoptosis. Finally, the mechanism underlying the changes in the FOXO family under the combined effects of both reproductive and oxidative stress remains unclear. It can only be demonstrated that JNK undergoes dephosphorylation of FOXO1 under the action of CAMP and ROS when oxidative stress occurs to induce it to enter the nucleus and promote apoptosis. When progesterone is reduced, nuclear translocation occurs in FOXO1, and it is phosphorylated

mitochondria activate the inflammatory ASK1-P-p38 MAPK pathway [122]. The recent literature has identified the physiologic aging of fetal tissues as a potential mechanistic feature of normal parturition. This process is affected by telomere-dependent and p38 MAPK-induced senescence activation (Fig. 7). Pregnancy-associated risk factors can cause pathologic activation of this pathway, causing OS-induced p38 MAPK activation and leading to senescence and premature aging of fetal tissues [123, 124].

It has been reported that the activation of ERK was increased in endometriotic tissue, suggesting that ERK might play a role in endometriosis pathogenesis, and phosphorylated ERK is increased in primary eutopic epithelial cells $[125,126]$. Prolonged phosphorylation of ERK in endometrial stromal cells occurs in women with endometriosis, compared with women without endometriosis [127]. Therefore, the endometriotic microenvironment could induce increased ERK activity in ectopic cells. Although only IL-1 $\beta$-induced cyclo-oxygenase 2 (COX2) production and IL-8 secretion could be attenuated by the ERK1/2-specific inhibitor PD98059, both TNF- $\alpha$ and IL- $1 \beta$ activate ERK and induce the expression of IL-8 and IL-6 [128]. However, another study found that the IL-1 $\beta$-mediated COX2 expression was not affected when ERK inhibition occurs in endometriotic stromal cells, but it occurred rather through p38 MAPK activation [129]. OS may also contribute to ERK activation. $\mathrm{H}_{2} \mathrm{O}_{2}$ induces ERK phosphorylation in endometriotic stromal cells with a more serious induction compared with stromal cells from women who do not have endometriosis [130]. Today, although, no direct relationship between phosphorylated ERK (p-ERK) activation and OS is confirmed, an increase in OS markers is discovered in epithelial and stromal cells derived from women with endometriosis in a similar pattern to p-ERK level (Table 2).

\section{Conclusion}

Based on the above, OS influences the entire reproductive process of woman. The production of excessive ROS leads to OS events. ROS, including superoxide $\left(\mathrm{O}_{2}{ }^{-} \bullet\right)$, hydrogen peroxide $\left(\mathrm{H}_{2} \mathrm{O}_{2}\right)$ and hydroxyl $(\cdot \mathrm{OH})$, cause DNA damage, lipid per-oxidation and protein damage. The antioxidative system is activated when slight OS occurred, such as SOD and GPx. In addition, when ROS levels exceed the scavenging capacity of the system, the redox system can repair oxidized and damage molecules using NADPH as an original electron source in such situations. Thus, the maintenance of high redox potential is a prerequisite for maintaining the reproductive systems in a healthy state [15].

In this review, we mainly introduced the relative reproductive diseases caused by OS and a series of signaling pathways, including in PCOS, endometriosis, 
preeclampsia and so on. They switch on a variety of molecules, including NF-кB, MAPK, FOXO and Keap1-Nrf2. In the above descriptions, we found that the role of each molecule is not independent and that they will form networks and interactions between them, leading to the complexity of signal molecule research. The OS that occurs during reproduction activates many molecules, but the interaction among them is not very clear, requiring us to determine the signaling cues in other organs or other diseases.

It is speculated that we know that the FOXO protein family is involved in the signaling pathways of Keap1Nrf2 and NF-кB. There are also subtle relationships between the various subtypes of the MAPK family. Therefore, regarding OS in the reproductive process, we can verify these viewpoints to better address the relationship between OS and reproductive harm. A large part of reproductive disease is caused by inflammation in the reproductive organs, leading to changes in the inflammatory factors that promote the body's protection or, in severe cases, promote cell death.

Compared to other diseases, disease research in the reproductive system is complicated, especially in humans or females during pregnancy. This complexity requires us to concretize the experimental period and break it down. In this discussion, we summarize the following. First, OS is involved in the development of diseases of the reproductive system, and it plays the role of a double-edged sword. Second, to a large extent, OS impairs the reproductive organs, including the placenta. Third, the inflammatory environment caused by OS causes a series of signal activations in the uterus. Fourth, the connection between OS and progesterone causes the reproductive process to become obstructed. Finally, we can re-examine the future development trends in reproductive system diseases by speculating on the relationship between these signaling molecules.

Female animals also undergo complex reproductive changes during the course of their illnesses and their deaths. In this review, the follicular development of animals, the development of fertilized eggs, and the processes of hormone changes are demonstrated. OS-related reproductive diseases have also been elucidated. By speculating on the changes in other diseases and on the factors related to reproductive diseases in cells in the face of reproductive system diseases, this article provides some institutional recommendations. This common point of these signals is that they are activated during inflammatory processes induced by OS. Under the influence of TNF- $\alpha$, cAMP messengers are activated, causing massive release of ROS in the mitochondria and deposition in the cytoplasm. Further, NF-kB, FOXO, and the MAPK family are induced. IKK $\beta$ releases NF- $\kappa B$ into the nucleus, resulting in a large number of cytokines increasing and promoting apoptosis. Further, FOXO3 directs the activation of $\mathrm{BCL} 10$, thus controlling NF- $\mathrm{BB}$ activity, but it is also activated through AKT pathway. ROS activate JNK to target phosphorylated FOXO1 in the cytoplasm to promote transcription into the nucleus. Progesterone's antiproliferative effect on uterine epithelial cells is affected by FOXO1, and an increase in progesterone activates FOXO1 to release into the nucleus. Under the influence of TNF- $\alpha$ and IL- $1 \beta$, the MAPK family is activated. When ERK is inhibited, p38 MAPK joins the battle, playing the same role as ERK.

In addition, Nrf2 plays an important role in mitigating OS-induced cellular dysfunction and developmental defects. Continued exposure to OS in postnatal and later life periods can further exacerbate the loss of Nrf2-regulated antioxidant defenses established in utero and thereby enhance susceptibility to disease in offspring. The Nrf2 antioxidant defense pathway might therefore provide a therapeutic target for ameliorating OS associated with adverse pregnancies and could provide an opportunity to modulate developmental priming via OS.

Although Nrf2 is a master regulator of cellular redox homeostasis following stress, Nrf2 activity in vascular and other cell types is known to decline [131] and could play an important role in age-related cellular dysfunction and disease onset. As highlighted by Zhang et al. in a special issue [132], the molecular mechanisms underlying the loss of response to OS by the Keap1-Nrf2 defense pathway in aging remain to be elucidated. Keap1-Nrf2 is the most classical pathway in OS, and it has also been shown in recent studies to play an important role in fetal development.

In conclusion, FOXO, as a key node of the signaling pathway, plays an important role in the signaling network and is a factor worth studying.

\section{Future directions}

In the future, a strategy to reinforce the antioxidant defense system and target the mitochondria will be a huge step. To increase the antioxidant capacity of the body, we must decrease the production of ROS from the mitochondrial electron transport chain that occurs in response to high glucose and fatty acid levels and decrease ROS production without significantly affecting ATP production. At the same time, we should increase the degradation of intracellular ROS and increase the bioavailability of antioxidants, and their passage through the barriers must be considered. Targeting the mitochondria and increase its overall antioxidant defense system will be a challenge. It is now considered certain that the pharmacological effects of antioxidants depend on their targeting. The delivery of antioxidants to mitochondria is a field of active research [133]. 
In addition, if these signaling molecules were studied completely, we would develop many blocking agents to prevent the occurrence of damage. ROS-activated JNK molecules and their downstream FOXO transcription factors (also involved in reproductive events) are worth exploring. In addition, OS-induced NF- $\mathrm{kB}$ signaling molecules should be linked to the molecules of the reproductive process, and for the future better study of reproductive diseases, drugs have very important research value. As we all know, an increasing number of social diseases attack our bodies, and some aging questions also perplex us. The mechanisms described in this review have important implications for these diseases, and the silence of certain factors in the FOXO family can cause activation of the antioxidant mechanism, the role of which in tumor diseases cannot be underestimated, so the study of OS in the study of cell protection mechanisms is unique and critical for the mechanism of disease.

\section{Abbreviations}

8-OHDG: 8-hydroxy-deoxyguanosine; BCL10: B-cell lymphoma/leukemia 10; CAT: Catalase; CL: Corpus luteum; CORT: Corticosterone; COX2: Cyclo-oxygenase 2; Cu-Zn SOD: Copper-zinc SOD; ERK1/2: Extracellular regulated kinase 1/2;

ETC: Electron transport chain; FSH: Follicle-stimulating hormone;

GCLC: Glutamate-cysteine ligase subunit catalysis; GPx: Glutathione peroxidase; GSR: Glutathione reductase; HCG: Human chorionic gonadotropin; HO-1: Heme oxygenase 1; IGFBP1: Insulin-like growth factor-binding protein 1; IKK: Inhibitor of nuclear factor kappa-B kinase; IUGR: Intrauterine growth restriction; JNK: Jun $\mathrm{N}$-terminal kinase; Keap1: Kelch-like ECH-associated protein 1; MAPK: Mitogenactivated protein kinase; MCP-1: Monocyte chemoattractant protein-1; MDA: Malondialdehyde; MIF: Migration inhibitory factor; MnSoD: Manganese superoxide dismutase; NAC: N-acetylcysteine; NADP(H): Nicotinamide adenine dinucleotide phosphate; NF-kB: Nuclear factor-kappa B; NQO1: NAD(P)H dehydrogenase (quinone 1): OS: Oxidative stress; Ox-LDL: Oxidized LDL PCOS: Polycystic ovary syndrome; PGF $2 \alpha$ : Prostaglandin-F-2 $\alpha$; PRL: Prolactin; SO: Superoxide; SOD: Superoxide dismutase; TAS: Total antioxidant status; TNFa: Tumor necrosis factor-a; uNK: Uterine natural killer; VEGF: Vascular endothelial growth factor

\section{Acknowledgements}

The finalization of this article relies on the opinions of the authors of all of the papers. We are very grateful for their contributions to this article. In addition, the present study was supported by the National Natural Science Foundation of China (grant nos. 31572476, 31272483, 31372332) and National Natural Science Foundation of Beijing (grant no. 6172022).

\section{Funding}

The present study was supported by the National Natural Science Foundation of China (grant nos. 31572476, 31272483, 31372332) and the National Natural Science Foundation of Beijing (grant no. 6172022).

\section{Availability of data and materials}

All of the data supporting the conclusions of this article are included in this published article.

\section{Authors' contributions}

JYL and YLD contributed to the initial literature search, acquisition of data, analysis and design of the first draft of the article. YXC and ZXW were included in reviewing the manuscript and further revision of it. JC was mainly responsible for designing illustrations and graphs, and YLD proofread the final manuscript before submission. All of the authors read and approved the final manuscript.

Ethics approval and consent to participate

Not applicable.
Consent for publication

Not applicable.

\section{Competing interests}

The authors declare that they have no competing interests.

\section{Publisher's Note}

Springer Nature remains neutral with regard to jurisdictional claims in published maps and institutional affiliations.

Received: 9 May 2018 Accepted: 23 July 2018

Published online: 20 August 2018

\section{References}

1. Burton GJ, Jauniaux E. Oxidative stress. Best Practice \& Research Clinical Obstetrics \& Gynaecology. 2011;25:287-99.

2. Cindrova-Davies T, Yung HW, Johns J, Spasic-Boskovic O, Korolchuk S, Jauniaux E, Burton GJ, Charnock-Jones DS. Oxidative stress, gene expression, and protein changes induced in the human placenta during labor. Am J Pathol. 2007:171:1168-79.

3. Ruder EH, Hartman TJ, Goldman MB. Impact of oxidative stress on female fertility. Current Opinion in Obstetrics \& Gynecology. 2009;21:219-22.

4. Attaran M, Pasqualotto E, Falcone T, Goldberg JM, Miller KF, Agarwal A, Sharma RK. The effect of follicular fluid reactive oxygen species on the outcome of in vitro fertilization. International Journal of Fertility and Womens Medicine. 2000:45:314-20.

5. Szczepanska M, Kozlik J, Skrzypczak J, Mikolajczyk M. Oxidative stress may be a piece in the endometriosis puzzle. Fertil Steril. 2003;79:1288-93.

6. Van Langendonckt A, Casanas-Roux F, Donnez J. Oxidative stress and peritoneal endometriosis. Fertil Steril. 2002;77:861-70.

7. Pierce JD, Cackler AB, Arnett MG. Why should you care about free radicals? Rn. 2004;67:38-42.

8. Agarwal A. Role of oxidative stress in endometriosis. Reprod BioMed Online. 2006;13:126-34.

9. Agarwal A, Allamaneni SSR. Role of free radicals in female reproductive diseases and assisted reproduction. Reprod BioMed Online. 2004;9:338-47.

10. Gupta S, Agarwal A, Banerjee J, Alvarez JG. The role of oxidative stress in spontaneous abortion and recurrent pregnancy loss: a systematic review. Obstetrical \& Gynecological Survey. 2007;62:335-47.

11. Agarwal A, Gupta S, Sekhon L, Shah R. Redox considerations in female reproductive function and assisted reproduction: from molecular mechanisms to health implications. Antioxid Redox Signal. 2008;10:1375-403.

12. Valko M, Leibfritz D, Moncol J, Cronin MTD, Mazur M, Telser J. Free radicals and antioxidants in normal physiological functions and human disease. Int $J$ Biochem Cell Biol. 2007;39:44-84.

13. Banks WJ. Applied veterinary histology. 2nd ed. Baltimore, MD: William and Wilkins; 1981.

14. Al-Gubory KH, Fowler PA, Garrel C. The roles of cellular reactive oxygen species, oxidative stress and antioxidants in pregnancy outcomes. Int J Biochem Cell Biol. 2010:42:1634-50.

15. Fujii J, luchi Y, Okada F: Fundamental roles of reactive oxygen species and protective mechanisms in the female reproductive system. Reproductive Biology and Endocrinology 2005, 3:10\%18 Sep \%19 review \%! Fundamental roles of reactive oxygen species and protective mechanisms in the female reproductive system.

16. Murphy MP. How mitochondria produce reactive oxygen species. Biochem J. 2009:417:1-13.

17. Dhaunsi GS, Gulati S, Singh AK, Orak JK, Asayama K, Singh I. Demonstration of cu-ZN superoxide-dismutase in rat-liver peroxisomes - biochemical and immunochemical evidence. J Biol Chem. 1992;267:6870-3.

18. Oberley LW. Mechanism of the tumor suppressive effect of MnSOD overexpression. Biomed Pharmacother. 2005;59:143-8.

19. Harris ED. Regulation of antioxidant enzymes. FASEB J. 1992;6:2675-83.

20. Spallholz JE, Roveri A, Yan L, Boylan LM, Kang CR, Ursini F. Glutathioneperoxidase and phospholipid HYDROPEROXIDE glutathione-peroxidase in tissues of BALB/c mice. FASEB J. 1991;5:A714.

21. Proctor PH, Reynolds ES. Free-radicals and disease in man. Physiol Chem Phys Med NMR. 1984;16:175-95.

22. Davies KJA, Wiese AG, Sevanian A, Kim EH: REPAIR SYSTEMS IN OXIDATIVE STRESS. Finch, C E and T E Johnson (Ed) Ucla (University of California-Los Angeles) Symposia on Molecular and Cellular Biology New Series, Vol 123 
Molecular Biology of Aging; Colloquium, Sante Fe, New Mexico, USA, March 4-10, 1989 Xvii+430p Wiley-Liss: New York, New York, USA Illus 1990:123-142

23. Ketterer B, Meyer DJ. Glutathione TRANSFERASE - a possible role in the DETOXICATION and repair of DNA and lipid HYDROPEROXIDES. Mutat Res. 1989:214:33-40

24. Kurlak LO, Green A, Loughna P, Pipkin FB. Oxidative stress markers in hypertensive states of pregnancy: preterm and term disease. Front Physiol. 2014;5:310.

25. Sharma RK, Agarwal A. Role of reactive oxygen species in gynecologic diseases. Reproductive Medicine and Biology. 2004;3:177-99.

26. Ishikawa M. Oxygen radicals-superoxide dismutase system and reproduction medicine. Nihon Sanka Fujinka Gakkai zasshi. 1993:45:842-8.

27. Shkolnik K, Tadmor A, Ben-Dor S, Nevo N, Galiani D, Dekel N. Reactive oxygen species are indispensable in ovulation. Proc Natl Acad Sci U S A. 2011;108:1462-7.

28. Suzuki T, Sugino N, Fukaya T, Sugiyama S, Uda T, Takaya R, Yajima A, Sasano $\mathrm{H}$. Superoxide dismutase in normal cycling human ovaries: immunohistochemical localization and characterization. Fertil Steril. 1999;72:720-6.

29. Tamate K, Sengoku K, Ishikawa M. The role of superoxide dismutase in the human ovary and fallopian tube. J Obstet Gynaecol (Tokyo 1995). 1995;21:401-9.

30. Geva E, Jaffe RB. Role of angiopoietins in reproductive tract angiogenesis. Obstetrical \& Gynecological Survey. 2000;55:511-9.

31. Gordon JD, Mesiano S, Zaloudek CJ, Jaffe RB. Vascular endothelial growth factor localization in human ovary and fallopian tubes: possible role in reproductive function and ovarian cyst formation. J Clin Endocrinol Metab. 1996;81:353-9.

32. Albrecht ED, Babischkin JS, Lidor Y, Anderson LD, Udoff LC, Pepe GJ. Effect of estrogen on angiogenesis in co-cultures of human endometrial cells and microvascular endothelial cells. Hum Reprod. 2003;18:2039-47.

33. Ushio-Fukai M, Alexander RW. Reactive oxygen species as mediators of angiogenesis signaling - role of $\mathrm{NAD}(\mathrm{P}) \mathrm{H}$ oxidase. Mol Cell Biochem. 2004:264:85-97.

34. Miyazaki T, Sueoka K, Dharmarajan AM, Atlas SJ, Bulkley GB, Wallach EE. Effect of inhibition of oxygen free-radical on ovulation and progesterone production by the INVITRO perfused rabbit ovary. J Reprod Fertil. 1991;91:207-12.

35. Behrman HR, Kodaman PH, Preston SL, Gao SP. Oxidative stress and the ovary. J Soc Gynecol Investig. 2001;8:S40-2.

36. Richards JS. Hormonal control of gene expression in the ovary. Endocr Rev. 1994;15:725-51.

37. Du BT, Takahashi K, Ishida GM, Nakahara K, Saito H, Kurachi H. Usefulness of intralovarian artery pulsatility and resistance indices measurement on the day of follicle aspiration for the assessment of oocyte quality. Fertil Steril. 2006;85:366-70.

38. Sugino N. Roles of reactive oxygen species in the corpus luteum. Anim Sci J. 2006;77:556-65.

39. Agarwal A, Aponte-Mellado A, Premkumar BJ, Shaman A, Gupta S. The effects of oxidative stress on female reproduction: a review. Reprod Biol Endocrinol. 2012;10:31.

40. Ahmed A, Cudmore MJ. Can the biology of VEGF and haem oxygenases help solve pre-eclampsia? Biochem Soc Trans. 2009;37:1237-42.

41. Szpera-Gozdziewicz A, Breborowicz GH. Endothelial dysfunction in the pathogenesis of pre-eclampsia. Frontiers in Bioscience-Landmark. 2014; 19:734-46.

42. Morohashi K, lida H, Nomura M, Hatano O, Honda S, Tsukiyama T, Niwa O, Hara T, Takakusu A, Shibata Y, Omura T. Functional difference between $\mathrm{AD} 4 \mathrm{BP}$ and ELP, and their distributions in STEROIDOGENIC tissues. Mol Endocrinol. 1994:8:643-53.

43. Vega M, Carrasco I, Castillo T, Troncoso JL, Videla LA, Devoto L. Functional LUTEOLYSIS in response to hydrogen-peroxide in human luteal cells. J Endocrinol. 1995;147:177-82.

44. Tamura H, Takasaki A, Miwa I, Tanoguchi K, Maekawa R, Asada H, Taketani T, Matsuoka A, Yamagata Y, Shimamura K, et al. Oxidative stress impairs oocyte quality and melatonin protects oocytes from free radical damage and improves fertilization rate. J Pineal Res. 2008;44:280-7.

45. Fauser B, Chang J, Azziz R, Legro R, Dewailly D, Franks S, Tarlatzis BC, Fauser B, Balen A, Bouchard P, et al. Revised 2003 consensus on diagnostic criteria and long-term health risks related to polycystic ovary syndrome (PCOS). Hum Reprod. 2004(19):41-7.

46. Costello MF, Shrestha B, Eden J, Johnson NP, Sjoblom P. Metformin versus oral contraceptive pill in polycystic ovary syndrome: a Cochrane review. Hum Reprod. 2007;22:1200-9.
47. Hilali N, Vural M, Camuzcuoglu H, Camuzcuoglu A, Aksoy N. Increased prolidase activity and oxidative stress in PCOS. Clin Endocrinol. 2013;79:105-10.

48. Cimino I, Casoni F, Liu X, Messina A, Parkash J, Jamin SP, Catteau-Jonard S, Collier F, Baroncini M, Dewailly D, et al. Novel role for anti-Mullerian hormone in the regulation of $\mathrm{GnRH}$ neuron excitability and hormone secretion. Nat Commun. 2016;7:10055.

49. Franks S, Mc Carthy M, Hardy K. Development of polycystic ovary syndrome: involvement of genetic and environmental factors. Int J Androl. 2006;29: 278-85.

50. Escobar-Morreale HF, Luque-Ramírez M, San Millán JL. The moleculargenetic basis of functional hyperandrogenism and the polycystic ovary syndrome. Endocr Rev. 2005;26:251-82.

51. Bremer AA, Miller WL. The serine phosphorylation hypothesis of polycystic ovary syndrome: a unifying mechanism of hyperandrogenemia and insulin resistance. Fertil Steril. 2008:89:1039-48.

52. Myatt L, Cui XL. Oxidative stress in the placenta. Histochem Cell Biol. 2004; 122:369-82.

53. Wisdom SJ, Wilson R, McKillop JH, Walker JJ. Antioxidant systems in normalpregnancy and in pregnancy-induced hypertension. Am J Obstet Gynecol. 1991;165:1701-4.

54. Wang Y, Walsh SW. Placental mitochondria as a source of oxidative stress in pre-eclampsia. Placenta. 1998;19:581-6.

55. Jauniaux $E$, Gulbis B, Burton GJ. The human first trimester gestational sac limits rather than facilitates oxygen transfer to the foetus--a review. Placenta. 2003;24(Suppl A):S86-93.

56. Lim KH, Zhou Y, Janatpour M, McMaster M, Bass K, Chun SH, Fisher SJ. Human cytotrophoblast differentiation/invasion is abnormal in pre-eclampsia. Am J Pathol. 1997:151:1809-18.

57. Jaffe $R$, Jauniaux $E$, Hustin J. Maternal circulation in the first-trimester human placenta - myth or reality? Am J Obstet Gynecol. 1997;176:695-705.

58. Jauniaux E, Watson AL, Hempstock J, Bao YP, Skepper JN, Burton GJ. Onset of maternal arterial blood flow and placental oxidative stress - a possible factor in human early pregnancy failure. Am J Pathol. 2000;157:2111-22.

59. Sultana Z, Maiti K, Aitken J, Morris J, Dedman L, Smith R. Oxidative stress, placental ageing-related pathologies and adverse pregnancy outcomes. Am J Reprod Immunol. 2017:77: e12653.

60. Witorsch RJ. Effects of elevated glucocorticoids on reproduction and development: relevance to endocrine disruptor screening. Crit Rev Toxicol. 2016:46:420-36

61. Preutthipan S, Chen SH, Tilly JL, Kugu K, Lareu RR, Dharmarajan AM. Inhibition of nitric oxide synthesis potentiates apoptosis in the rabbit corpus luteum. Reprod BioMed Online. 2004;9:264-70.

62. Ghafourifar P, Richter C. Nitric oxide synthase activity in mitochondria. FEBS Lett. 1997;418:291-6.

63. Wang YP, Walsh SW, Guo JD, Zhang JY. Maternal levels of prostacyclin, thromboxane, vitamin-E, and lipid peroxides throughout normal-pregnancy. Am J Obstet Gynecol. 1991;165:1690-4.

64. Menon R, Fortunato SJ, Yu J, Milne GL, Sanchez S, Drobek CO, Lappas M, Taylor RN. Cigarette smoke induces oxidative stress and apoptosis in normal term fetal membranes. Placenta. 2011;32:317-22.

65. Sbrana E, Suter MA, Abramovici AR, Hawkins HK, Moss JE, Patterson L, Shope C, Aagaard-Tillery K. Maternal tobacco use is associated with increased markers of oxidative stress in the placenta. Am J Obstet Gynecol. 2011;205:7

66. Smith R, Maiti K, Aitken RJ. Unexplained antepartum stillbirth: a consequence of placental aging? Placenta. 2013;34:310-3

67. Oner-lyidogan Y, Kocak H, Gurdol F, Korkmaz D, Buyru F. Indices of oxidative stress in eutopic and ectopic endometria of women with endometriosis. Gynecol Obstet Investig. 2004;57:214-7.

68. Ota H, Igarashi S, Tanaka T. Xanthine oxidase in eutopic and ectopic endometrium in endometriosis and adenomyosis. Fertil Steril. 2001;75: 785-90.

69. Agarwal A, Gupta S, Sikka S. The role of free radicals and antioxidants in reproduction. Current Opinion in Obstetrics \& Gynecology. 2006;18:325-32.

70. Bedaiwy MA, Falcone T, Sharma RK, Goldberg JM, Attaran M, Nelson DR, Agarwal A. Prediction of endometriosis with serum and peritoneal fluid markers: a prospective controlled trial. Hum Reprod. 2002;17:426-31.

71. Mier-Cabrera J, Jimenez-Zamudio L, Garcia-Latorre E, Cruz-Orozco O, Hernandez-Guerrero C. Quantitative and qualitative peritoneal immune profiles, T-cell apoptosis and oxidative stress-associated characteristics in women with minimal and mild endometriosis. BJOG. 2011;118:6-16. 
72. Kajihara H, Yamada Y, Kanayama S, Furukawa N, Noguchi T, Haruta S, Yoshida S, Sado T, Oi H, Kobayashi H. New insights into the pathophysiology of endometriosis: from chronic inflammation to danger signal. Gynecol Endocrinol. 2011;27:73-9.

73. Li YQ, Zhang ZX, Xu YJ, Ni W, Chen SX, Yang Z, Ma D. N-acetyl-L-cysteine and pyrrolidine dithiocarbamate inhibited nuclear factor-kappa B activation in alveolar macrophages by different mechanisms. Acta Pharmacol Sin. 2006;27:339-46.

74. Ngo C, Chereau C, Nicco C, Weill B, Chapron C, Batteux F. Reactive oxygen species controls endometriosis progression. Am J Pathol. 2009;175:225-34.

75. McCubrey JA, LaHair MM, Franklin RA. Reactive oxygen species-induced activation of the MAP kinase signaling pathways. Antioxid Redox Signal. 2006:8:1775-89.

76. Madazli R, Benian A, Aydin S, Uzun H, Tolun N. The plasma and placental levels of malondialdehyde, glutathione and superoxide dismutase in preeclampsia. J Obstet Gynaecol. 2002;22:477-80.

77. Matsubara K, Higaki T, Matsubara Y, Nawa A. Nitric oxide and reactive oxygen species in the pathogenesis of preeclampsia. Int J Mol Sci. 2015;16:4600-14.

78. Roberts JM, Taylor RN, Musci TJ, Rodgers GM, Hubel CA, McLaughlin MK Preeclampsia - an endothelial-cell disorder. Am J Obstet Gynecol. 1989;161: 1200-4.

79. Hubel CA, Roberts JM, Taylor RN, Musci TJ, Rogers GM, McLaughlin MK. Lipid-peroxidation in pregnancy - new perspectives on preeclampsia. Am J Obstet Gynecol. 1989;161:1025-34.

80. Uzun H, Benian A, Madazli R, Topcuoglu MA, Aydin S, Albayrak M. Circulating oxidized low-density lipoprotein and paraoxonase activity in preeclampsia. Gynecol Obstet Investig. 2005;60:195-200.

81. Wallukat G, Homuth V, Fischer T, Lindschau C, Horstkamp B, Jupner A, Baur E, Nissen E, Vetter K, Neichel D, et al. Patients with preeclampsia develop agonistic autoantibodies against the angiotensin AT(1) receptor. J Clin Investig. 1999;103:945-52.

82. Griendling KK, Sorescu D, Lassegue B, Ushio-Fukai M. Modulation of protein kinase activity and gene expression by reactive oxygen species and their role in vascular physiology and pathophysiology. Arterioscler Thromb Vasc Biol. 2000;20:2175-83.

83. Raijmakers MTM, Peters WHM, Steegers EAP, Poston L. NAD(P)H oxidase associated superoxide production in human placenta from normotensive and pre-eclamptic women. Placenta. 2004;25:585-9.

84. Walsh SW. Eicosanoids in preeclampsia. Prostaglandins Leukotrienes and Essential Fatty Acids. 2004;70:223-32.

85. Klemmensen AK, Tabor A, Osterdal ML, Knudsen VK, Halldorsson TI, Mikkelsen TB, Olsen SF. Intake of vitamin C and $\mathrm{E}$ in pregnancy and risk of pre-eclampsia: prospective study among 57346 women. BJOG. 2009;116:964-74.

86. Liu GH, Dong YL, Wang ZX, Cao J, Chen YX. Restraint stress delays endometrial adaptive remodeling during mouse embryo implantation. Stress-the International Journal on the Biology of Stress. 2015;18:699-709.

87. Liu GH, Dong YL, Wang ZX, Cao J, Chen YX. Restraint stress alters immune parameters and induces oxidative stress in the mouse uterus during embryo implantation. Stress-the International Journal on the Biology of Stress. 2014;17:494-503.

88. Perucci LO, Correa MD, Dusse LM, Gomes KB, Sousa LP. Resolution of inflammation pathways in preeclampsia-a narrative review. Immunol Res. 2017;65:774-89.

89. Wu F, Tian FJ, Lin Y. Oxidative stress in placenta: health and diseases. Biomed Res Int. 2015;2015:293271.

90. Wojsiat J, Korczynski J, Borowiecka M, Zbikowska HM. The role of oxidative stress in female infertility and in vitro fertilization. Postepy Hig Med Dosw (Online). 2017;71:359-66.

91. Itoh K, Chiba T, Takahashi S, Ishii T, Igarashi K, Katoh Y, Oyake T, Hayashi N, Satoh K, Hatayama I, et al. An Nrf2/small Maf heterodimer mediates the induction of phase II detoxifying enzyme genes through antioxidant response elements. Biochem Biophys Res Commun. 1997;236:313-22.

92. Itoh K, Wakabayashi N, Katoh Y, Ishii T, Igarashi K, Engel JD, Yamamoto M. Keap1 represses nuclear activation of antioxidant responsive elements by Nrf2 through binding to the amino-terminal Neh2 domain. Genes Dev. 1999;13:76-86.

93. Cho HY, Reddy SP, Debiase A, Yamamoto M, Kleeberger SR. Gene expression profiling of NRF2-mediated protection against oxidative injury. Free Radic Biol Med. 2005:38:325-43

94. Ishii T, Itoh K, Takahashi S, Sato H, Yanagawa T, Katoh Y, Bannai S, Yamamoto M. Transcription factor Nrf2 coordinately regulates a group of oxidative stressinducible genes in macrophages. J Biol Chem. 2000;275:16023-9.
95. Cheng XH, Chapple SJ, Patel B, Puszyk W, Sugden D, Yin XK, Mayr M, Siow RCM, Mann GE. Gestational diabetes mellitus impairs Nrf2-mediated adaptive antioxidant defenses and redox signaling in fetal endothelial cells in utero. Diabetes. 2013;62:4088-97.

96. Lim R, Barker G, Lappas M. The transcription factor Nrf2 is decreased after spontaneous term labour in human fetal membranes where it exerts antiinflammatory properties. Placenta. 2015;36:7-17.

97. Kansanen E, Kuosmanen SM, Leinonen H, Levonen AL. The Keap1-Nrf2 pathway: mechanisms of activation and dysregulation in cancer. Redox Biol. 2013;1:45-9.

98. Guan L, Zhang L, Gong ZC, Hou XN, Xu YX, Feng XH, Wang HY, You H. FoxO3 inactivation promotes human Cholangiocarcinoma tumorigenesis and Chemoresistance through Keap1-Nrf2 signaling. Hepatology. 2016;63: 1914-27.

99. Gilmore TD. Introduction to NF-kappaB: players, pathways, perspectives. Oncogene. 2006;25:6680-4.

100. Hayden MS, West AP, Ghosh S. NF-kappa B and the immune response. Oncogene. 2006;25:6758-80.

101. Haddad JJ. Oxygen-sensing mechanisms and the regulation of redoxresponsive transcription factors in development and pathophysiology. Respir Res. 2002;3:27.

102. Scheidereit C. IkappaB kinase complexes: gateways to NF-kappaB activation and transcription. Oncogene. 2006;25:6685-705

103. Hu MCT, Lee DF, Xia WY, Golfman LS, Fu OY, Yang JY, Zou YY, Bao SL, Hanada N, Saso H, et al. I kappa B kinase promotes tumorigenesis through inhibition of forkhead FOXO3a. Cell. 2004;117:225-37.

104. Li Z, Zhang H, Chen Y, Fan L, Fang J. Forkhead transcription factor FOXO3a protein activates nuclear factor kappaB through B-cell lymphoma/leukemia 10 (BCL10) protein and promotes tumor cell survival in serum deprivation. J Biol Chem. 2012;287:17737-45.

105. Sakamoto Y, Harada T, Horie S, Iba Y, Taniguchi F, Yoshida S, Iwabe T, Terakawa N. Tumor necrosis factor-alpha-induced interleukin-8 (IL-8) expression in endometriotic stromal cells, probably through nuclear factor-kappa $\mathrm{P}$ activation: gonadotropin-releasing hormone agonist treatment reduced IL-8 expression. J Clin Endocrinol Metab. 2003;88: $730-5$.

106. Lousse JC, Van Langendonckt A, Gonzalez-Ramos R, Defrere S, Renkin E, Donnez J. Increased activation of nuclear factor-kappa B (NF-kappa B) in isolated peritoneal macrophages of patients with, endometriosis. Fertil Steril. 2008;90:217-20

107. Veillat V, Lavoie $\mathrm{CH}$, Metz CN, Roger T, Labelle Y, Akoum A. Involvement of nuclear factor-kappa B in macrophage migration inhibitory factor gene transcription up-regulation induced by interleukin-1 beta in ectopic endometrial cells. Fertil Steril. 2009;91:2148-56.

108. Cao WG, Morin M, Sengers V, Metz C, Roger T, Maheux R, Akoum A. Tumour necrosis factor-alpha up-regulates macrophage migration inhibitory factor expression in endometrial stromal cells via the nuclear transcription factor NF-kappa B. Hum Reprod. 2006;21:421-8.

109. Grund EM, Kagan D, Tran CA, Zeitvogel A, Starzinski-Powitz A, Nataraja S, Palmer SS. Tumor necrosis factor-alpha regulates inflammatory and mesenchymal responses via mitogen-activated protein kinase kinase, p38, and nuclear factor kappa B in human endometriotic epithelial cells. Mol Pharmacol. 2008;73:1394-404.

110. Brunet A, Bonni A, Zigmond MJ, Lin MZ, Juo P, Hu LS, Anderson MJ, Arden KC, Blenis J, Greenberg ME. Akt promotes cell survival by phosphorylating and inhibiting a Forkhead transcription factor. Cell. 1999;96:857-68.

111. Van Der Vos KE, Coffer PJ. The extending network of FOXO transcriptional target genes. Antioxid Redox Signal. 2011;14:579-92.

112. Goto T, Takano M, Albergaria A, Briese J, Pomeranz KM, Cloke B, Fusi L, Feroze-Zaidi F, Maywald N, Sajin M, et al. Mechanism and functional consequences of loss of FOXO1 expression in endometrioid endometrial cancer cells. Oncogene. 2008;27:9-19.

113. Kajihara T, Brosens JJ, Ishihara O. The role of FOXO1 in the decidual transformation of the endometrium and early pregnancy. Med Mol Morphol. 2013;46:61-8.

114. Kajihara $T$, Jones M, Fusi L, Takano M, Feroze-Zaidi F, Pirianov G, Mehmet $H_{\text {, }}$ Ishihara O, Higham JM, Lam EW, Brosens JJ. Differential expression of FOXO1 and FOXO3a confers resistance to oxidative cell death upon endometrial decidualization. Mol Endocrinol. 2006;20:2444-55.

115. Kyo S, Sakaguchi J, Kiyono T, Shimizu Y, Maida Y, Mizumoto Y, Mori N, Nakamura M, Takakura M, Miyake K, et al. Forkhead transcription factor 
FOXO1 is a direct target of progestin to inhibit endometrial epithelial cell growth. Clin Cancer Res. 2011;17:525-37.

116. Gellersen B, Brosens J. Cyclic AMP and progesterone receptor cross-talk in human endometrium: a decidualizing affair. J Endocrinol. 2003;178:357-72.

117. Dijkers PF, Medema RH, Lammers JW, Koenderman L, Coffer PJ. Expression of the pro-apoptotic BCl-2 family member Bim is regulated by the forkhead transcription factor FKHR-L1. Curr Biol. 2000;10:1201-4.

118. Eijkelenboom A, Burgering BM. FOXOs: signalling integrators for homeostasis maintenance. Nat Rev Mol Cell Biol. 2013;14:83-97.

119. Leitao B, Jones MC, Fusi L, Higham J, Lee Y, Takano M, Goto T, Christian M, Lam EWF, Brosens JJ. Silencing of the JNK pathway maintains progesterone receptor activity in decidualizing human endometrial stromal cells exposed to oxidative stress signals. Faseb Journal. 2010;24:1541-51. \%1548 May $\% 1549$ Article \%! Silencing of the JNK pathway maintains progesterone receptor activity in decidualizing human endometrial stromal cells exposed to oxidative stress signals

120. Labied S, Kajihara T, Madureira PA, Fusi L, Jones MC, Higham JM, Varshochi R, Francis JM, Zoumpoulidou G, Essafi A, et al. Progestins regulate the expression and activity of the forkhead transcription factor FOXO1 in differentiating human endometrium. Mol Endocrinol. 2006;20:35-44.

121. Dhillon AS, Hagan S, Rath O, Kolch W. MAP kinase signalling pathways in cancer. Oncogene. 2007;26:3279-90

122. Lee CH, Ying TH, Chiou HL, Hsieh SC, Wen SH, Chou RH, Hsieh YH. Alphamangostin induces apoptosis through activation of reactive oxygen species and ASK1/p38 signaling pathway in cervical cancer cells. Oncotarget. 2017;8: 47425-39.

123. Bredeson S, Papaconstantinou J, Deford JH, Kechichian T, Syed TA, Saade GR, Menon R. HMGB1 promotes a p38MAPK associated non-infectious inflammatory response pathway in human fetal membranes. PLoS One. 2014:9:18.

124. Menon R, Papaconstantinou J. p38 mitogen activated protein kinase (MAPK): a new therapeutic target for reducing the risk of adverse pregnancy outcomes. Expert Opin Ther Targets. 2016;20:1397-412.

125. Matsuzaki S, Darcha C. Co-operation between the AKT and ERK signaling pathways may support growth of deep endometriosis in a fibrotic microenvironment in vitro. Hum Reprod. 2015;30:1606-16.

126. Yotova IY, Quan P, Leditznig N, Beer U, Wenzl R, Tschugguel W. Abnormal activation of Ras/Raf/MAPK and RhoA/ROCKIl signalling pathways in eutopic endometrial stromal cells of patients with endometriosis. Hum Reprod. 2011;26:885-97.

127. Velarde MC, Aghajanova L, Nezhat CR, Giudice LC. Increased mitogenactivated protein kinase kinase/extracellularly regulated kinase activity in human endometrial stromal fibroblasts of women with endometriosis reduces $3^{\prime}, 5^{\prime}$-cyclic adenosine $5^{\prime}$-monophosphate inhibition of cyclin D1. Endocrinology. 2009;150:4701-12

128. Yoshino O, Osuga Y, Hirota Y, Koga K, Hirata T, Harada M, Morimoto C, Yano T, Nishii O, Tsutsumi O, Taketani Y. Possible pathophysiological roles of mitogenactivated protein kinases (MAPKs) in endometriosis. Am J Reprod Immunol. 2004;52:306-11.

129. Huang F, Cao J, Liu Q, Zou Y, Li H, Yin T. MAPK/ERK signal pathway involved expression of COX-2 and VEGF by IL-1 beta induced in human endometriosis stromal cells in vitro. Int J Clin Exp Pathol. 2013;6:2129-36.

130. Andrade SS, Azevedo Ade C, Monasterio IC, Paredes-Gamero EJ, Goncalves GA, Bonetti TC, Albertoni G, Schor E, Barreto JA, Luiza Oliva M, et al. 17betaestradiol and steady-state concentrations of $\mathrm{H} 2 \mathrm{O}$ : antiapoptotic effect in endometrial cells from patients with endometriosis. Free Radic Biol Med. 2013;60:63-72

131. Rahman MM, Sykiotis GP, Nishimura M, Bodmer R, Bohmann D. Declining signal dependence of Nrf2-MafS-regulated gene expression correlates with aging phenotypes. Aging Cell. 2013;12:554-62.

132. Zhang HQ, Davies KJA, Forman HJ. Oxidative stress response and Nrf2 signaling in aging. Free Radic Biol Med. 2015;88:314-36.

133. Sheu SS, Nauduri D, Anders MW. Targeting antioxidants to mitochondria: a new therapeutic direction. Biochimica Et Biophysica Acta-Molecular Basis of Disease. 2006;1762:256-65.

Ready to submit your research? Choose BMC and benefit from:

- fast, convenient online submission

- thorough peer review by experienced researchers in your field

- rapid publication on acceptance

- support for research data, including large and complex data types

- gold Open Access which fosters wider collaboration and increased citations

- maximum visibility for your research: over $100 \mathrm{M}$ website views per year

At BMC, research is always in progress.

Learn more biomedcentral.com/submissions 